\title{
Sporadic Parkinson's disease derived neuronal cells show disease-specific mRNA and small RNA signatures with abundant deregulation of piRNAs
}

\author{
Markus Schulze ${ }^{1,4}$, Annika Sommer ${ }^{2}$, Sonja Plötz ${ }^{2}$, Michaela Farrell ${ }^{2}$, Beate Winner ${ }^{2}$, Janina Grosch³,
} Jürgen Winkler ${ }^{3}$ and Markus J. Riemenschneider ${ }^{1 *}$

\begin{abstract}
Differentiated neurons established via iPSCs from patients that suffer from familial Parkinson's disease (PD) have allowed insights into the mechanisms of neurodegeneration. In the larger cohort of patients with sporadic PD, iPSC based information on disease specific cellular phenotypes is rare. We asked whether differences may be present on genomic and epigenomic levels and performed a comprehensive transcriptomic and epigenomic analysis of fibroblasts, iPSCs and differentiated neuronal cells of sporadic PD-patients and controls. We found that on mRNA level, although fibroblasts and iPSCs are largely indistinguishable, differentiated neuronal cells of sporadic PD patients show significant alterations enriched in pathways known to be involved in disease aetiology, like the CREBpathway and the pathway regulating PGC1a. Moreover, miRNAs and piRNAs/piRNA-like molecules are largely differentially regulated in cells and post-mortem tissue samples between control- and PD-patients. The most striking differences can be found in piRNAs/piRNA-like molecules, with SINE- and LINE-derived piRNAs highly downregulated in a disease specific manner. We conclude that neuronal cells derived from sporadic PD-patients help to elucidate novel disease mechanisms and provide relevant insight into the epigenetic landscape of sporadic Parkinson's disease as particularly regulated by small RNAs.
\end{abstract}

Keywords: Methylation, PD, Induced pluripotent stem cells, iPSC, SINE, LINE

\section{Background}

Coding mutations like the well-known A53T $\alpha$-synuclein and G2019S LRRK2 mutations cause familial Parkinson's disease (PD) [38]. Dopaminergic neurons carrying these mutations obtained via an induced pluripotent stem cell (iPSC) intermediate have been shown to recapitulate hallmarks of the neurodegenerative process in PD like increased susceptibility to oxidative [42] and nitrosative stress [53].

Much less is known about the possibility to model sporadic PD with iPSC based models. In sporadic PD that constitutes about $90 \%$ of cases and where none of the well-known genes causing familial Parkinsonism is

\footnotetext{
* Correspondence: markus.riemenschneider@ukr.de

${ }^{1}$ Department of Neuropathology, Regensburg University Hospital,

Franz-Josef-Strauss-Allee 11, 93053 Regensburg, Germany

Full list of author information is available at the end of the article
}

mutated, no single variant in the whole coding sequence of the human genome was found to be associated with PD in a recent study [55]. In contrast, alterations in non-coding regions, which are enriched in PD-related genes, are well established risk factors for PD [12]. In addition, alterations of the epigenome in sporadic Parkinson's disease have been reported in brain tissue on methylation [25] and small RNA level [26] and epigenetic alterations are also present in the patients' peripheral blood [24]. Although iPSC reprogramming has been reported to remove all marks associated with cellular ageing [39], disease-specific alterations may survive reprogramming and then can impact iPSC function [16], even allowing for imprinting disorders to be modelled with iPSCs [7]. Importantly, both small RNAs [62] as well as methylation [43] can contribute to somatic memory. 
Differential expression of disease associated small RNAs in cultured, differentiated neurons would allow to recapitulate and to study epigenome-mediated pathological alterations. Mature miRNAs, which repress target gene functions both by regulating target mRNA levels as well as by repression of target mRNA translation, have already been implicated in the pathogenesis of Parkinson's disease, e.g. in animal models [47]. PIWI interacting RNAs, a class of small regulatory RNAs first described in the male germline [13], are less well studied in neuronal cells but have been implicated in retrotransposon silencing in the brain [41] as well as regulation of epigenetic modifications [49]. Importantly, piRNAs were recently described to be differentially regulated in Alzheimer's disease brain tissue [48, 52] connecting them to the process of neurodegeneration.

Most phenotypes observed in neurons differentiated from cells carrying a mutation that causes familial PD can only be observed after the cells have been stressed, implying that the alterations in the coding sequence lead to a stress-susceptible, primed state in the neurons. More specifically, increased cell death in neurons carrying the A53T mutation in $\alpha$-synuclein is observed after treatment with mitochondrial toxins [53] and in neurons carrying the G2019S LRRK2 mutation after $\mathrm{H}_{2} \mathrm{O}_{2}$ application [42].

Under certain circumstances, dopaminergic neurons derived from sporadic Parkinson's disease patients have been reported to show phenotypes similar to genetic cases including cellular abnormalities [54], altered methylation patterns [12] as well as abnormalities in protein turnover [18]. Importantly, the epigenomic alterations observed were present in pathways important for physiological neurodevelopment [12] supporting the hypothesis that these pathways are altered in PD [29] as has been reported for Alzheimer's disease [14]. The alterations in protein turnover were already present in fibroblasts [18] and a large subset of fibroblasts derived from sporadic PD cases showed increased sensitivity to valinomycin treatment [58]. As fibroblasts are frequently used for reprogramming to iPSCs followed by differentiation into neuronal cells, it is possible that an epigenetic signature survives reprogramming that potentially impacts the function of transplanted cells. More importantly, this signature -if present- might provide unique insights into the disease aetiology of sporadic PD. Therefore, the Bavarian Research Network Induced Pluripotent Stem Cells (ForIPS) was initiated to test the hypothesis, which -if any- phenotypes can be observed in cells derived from sporadic PD-patients.

Based on these premises, we examined a large region specific cohort of matched fibroblasts, iPSCs and differentiated neuronal cells from healthy individuals and Parkinson's disease patients and applied rigorous quality control standards. Previous to our analyses, we confirmed the
PD-patients to be negative for all known monogenic forms of the disease. We aimed to determine in a global and unbiased approach if there were any epigenetic marks that distinguish cells from healthy and diseased individuals. Indeed, we found that cells derived from sporadic Parkinson's disease patients show a unique small RNA signature and that pathways that are known to be altered in diseased tissue as well as genetic cases, like the pathway regulating PGC1 $\alpha$, are deregulated.

\section{Methods}

\section{Cell culture, iPSC generation and differentiation to midbrain neurons}

Induced pluripotent stem cells (iPSC) were generated from eight sporadic PD patients and six healthy controls by retroviral transduction of the four transcription factors (Oct 3/4, c-Myc, Sox2 and Klf4) as previously described [15]. The Institutional Review Board approval (Nr. 4120: Generierung von humanen neuronalen Modellen bei neurodegenerativen Erkrankungen) and informed consent forms are on file at the movement disorder clinic at the Department of Molecular Neurology, Universitätsklinikum Erlangen (Erlangen, Germany). All the hiPSC lines were cultured in mTeSR (Stemcell Technologies) or MACSbrew (Miltenyi) on Geltrex (Gibco ${ }^{\circledR}$ Thermo Fisher Scientific) and splitted every five to seven days using Collagenase IV or Gentle Cell Dissociation Reagent (Stemcell Technologies). Pluripotency and a stable karyotype were tested by flow cytometry and G-banding chromosomal analysis, respectively. One to two hiPSC clones per individual (Additional file 1: Table S1) were differentiated into small molecule neural precursor cells (smNPCs) following the protocol published by others [50] with some adaption as described in [59]. The smNPCs were further differentiated to midbrain neurons within three weeks of maturation [50, 59]. Briefly, 70\% confluent iPSC were detached by collagenase IV (Gibco ${ }^{\circ}$ Thermo Fisher Scientific) treatment for $20 \mathrm{~min}$ at $37{ }^{\circ} \mathrm{C}, 5 \% \mathrm{CO}_{2}$. Cell colonies were cultured as free-floating aggregates in human embryonic stem cells (hESC) medium (80\% KO-DMEM, $20 \%$ KO serum replacement, $1 \%$ non-essential amino acids, 1\% Penicillin/Streptavidin (all from Thermo Fisher Scientific), $1 \mathrm{mM}$ ß-Mercaptoethanol (Sigma-Aldrich) supplemented with the small molecules $1 \mu \mathrm{M}$ LDN (Stemgent), $10 \mu \mathrm{M}$ SB, $3 \mu \mathrm{M}$ Chir, and $0.5 \mu \mathrm{M}$ Purmorphoamine (PMA, all from Tocris) on ultra-low adhesion plates. After two days of incubation at $37{ }^{\circ} \mathrm{C}, 5 \% \mathrm{CO} 2$, the cell colonies were centred and the medium was changed to N2B27 medium (50\% DMEM/F12, 50\% Neurobasal Medium, 1:200 N2, 1:100 B27 (all from Thermo Fisher Scientific) supplemented with the same small molecules. On day four, the medium was changed to smNPC medium (N2B27 medium supplemented with 3 
uM Chir, $0.5 \mathrm{uM}$ PMA and $150 \mathrm{uM}$ Ascorbic acid (AA; Sigma-Aldrich). After a total of six days of suspension culture, cell colonies were replaced on geltrex-coated (Gibco $^{\circ}$ Thermo Fisher Scientific) 12-well plates in smNPC medium supplemented with Rho kinase inhibitor Y27532 (RI, Axxora) for $24 \mathrm{~h}$. Medium was changed every other day and cells were passaged once a week by accutase treatment. After at least five passages, smNPCs were differentiated into $\mathrm{MN}$. Therefore, two days after passaging, the medium was exchanged to N2B27 medium supplemented with $100 \mathrm{ng} / \mathrm{ml}$ FGF8 (Peprotech), $1 \mu \mathrm{M}$ PMA and $200 \mu \mathrm{M}$ AA. On day 10 of differentiation, medium was supplemented with $100 \mathrm{ng} / \mathrm{ml} \mathrm{FGF8,} 10 \mathrm{ng} / \mathrm{ml} \mathrm{GDNF}$ (Peprotech), 10 ng/ml TGFb (eBioscience), $200 \mathrm{uM} \mathrm{AA,}$ and $500 \mu \mathrm{M}$ Dibutyryl-cAMP (dbcAMP; Sigma-Aldrich. On the next day, cells were passaged at ratios of 1:2-1:3 as single cells after accutase treatment (Sigma-Aldrich), plated onto geltrex-coated four-well chamber slides (Ibidi) or 12-well plates and further cultured for at least two weeks in maturation medium (N2B27 medium plus 100 ng/ml FGF8, 10 ng/ml GDNF (Peprotech), 10 ng/ml TGFb (eBioscience), $200 \mathrm{uM}$ AA, and $500 \mu \mathrm{M}$ Dibutyryl-cAMP (dbcAMP; Sigma-Aldrich) with two times media change per week.

\section{Poly-a RNA library preparation}

Libraries for next-generation sequencing were prepared from $1 \mu \mathrm{g}$ total RNA with the TrueSeq RNA library preparation kit v2 according to the manufacturer's instructions (Illumina, San Diego, CA, USA). Briefly, poly-A RNA was purified from the total RNA preparation with magnetic oligo-dT beads. The RNA-bead mixture was incubated at $65{ }^{\circ} \mathrm{C}$ for five minutes to denature the RNA. Then, the mixture was incubated for five minutes at RT to allow the RNA to bind to the beads. Afterwards, the beads were washed with bead washing buffer and resuspended in elution buffer for two minutes at $80{ }^{\circ} \mathrm{C}$. Bead binding buffer was added to allow rebinding of the eluted RNA. The beads were washed with bead washing buffer and resuspended in elute, prime, fragment mix. The RNA was eluted at $94^{\circ}$ $\mathrm{C}$ for eight minutes, and first strand cDNA synthesis was performed with SuperScript II (Thermo Fisher Scientific, Waltham, MA, USA) in first strand mix supplied by Illumina. Second strand synthesis was performed with the second strand mix for one hour at $16{ }^{\circ} \mathrm{C}$ and the resulting double stranded cDNA was purified using AMPure XP beads (Beckman Coulter, Brea, CA, USA). Then, end repair was performed for $30 \mathrm{~min}$ at $30{ }^{\circ} \mathrm{C}$ with the provided end repair mix. The end repaired DNA was again cleaned up with AMPure XP beads. A-tailing was performed with the A-tailing mix at $37{ }^{\circ} \mathrm{C}$ for $30 \mathrm{~min}$ followed by $70{ }^{\circ} \mathrm{C}$ for five minutes. Indexed adapters were ligated to the end-repaired A-tailed cDNA at $30{ }^{\circ} \mathrm{C}$ for ten minutes. Next, stop ligation buffer was added and the libraries were cleaned up with AMPure XP beads. PCR amplification was performed with the provided PCR reagents and the following cycling conditions: Denaturation at $98{ }^{\circ} \mathrm{C}$ for $30 \mathrm{~s}$ and then 15 cycles of1) $98{ }^{\circ} \mathrm{C}$ for $\left.10 \mathrm{~s}, 2\right) 60{ }^{\circ} \mathrm{C}$ for $30 \mathrm{~s}$ and 3$) 72{ }^{\circ} \mathrm{C}$ for $30 \mathrm{~s}$. Afterwards, a final extension at $72{ }^{\circ} \mathrm{C}$ for five minutes was performed and the amplified libraries were purified again with AMPure XP beads. Finally, quality control was performed with a Bioanalyser (Agilent).

\section{RNA library preparation for tissue samples}

For all tissue samples (RIN usually $<8$ ), we used the TrueSeq RNA Access Kit (Illumina) to prepare libraries from $100 \mathrm{ng}$ total RNA, which is suitable for degraded RNA. First, first strand cDNA was synthetized with the Elute, Prime, Fragment High Mix and super script II in First Strand Master Mix $\left(25{ }^{\circ} \mathrm{C}\right.$ for $10 \mathrm{~min}, 42{ }^{\circ} \mathrm{C}$ for $15 \mathrm{~min}$ and $70{ }^{\circ} \mathrm{C}$ for $15 \mathrm{~min}$ ). Then, $20 \mu \mathrm{l} \mathrm{Second}$ Strand Marking Master Mix were added and the second strand was synthetized for $1 \mathrm{~h}$ at $16{ }^{\circ} \mathrm{C}$. The cDNA was cleaned up with AMPure XP beads and A-tailing was performed with A-tailing mix $\left(37^{\circ} \mathrm{C}\right.$ for $30 \mathrm{~min}$ followed by $5 \mathrm{~min}$ at $70^{\circ} \mathrm{C}$ ). Following this, adapter ligation was performed with Ligation Mix for $10 \mathrm{~min}$ at $30{ }^{\circ} \mathrm{C}$ after which the reaction was stopped with Stop Ligation Buffer. The libraries were cleaned up with AMPure XP beads and amplified with PCR Master Mix and PCR Primer Cocktail $\left(98^{\circ} \mathrm{C}\right.$ for $30 \mathrm{~s}, 15$ cycles of $98{ }^{\circ} \mathrm{C}$ for $10 \mathrm{~s}$, $60{ }^{\circ} \mathrm{C}$ for $30 \mathrm{~s}, 72{ }^{\circ} \mathrm{C}$ for $30 \mathrm{~s}$ and $72{ }^{\circ} \mathrm{C}$ for $5 \mathrm{~min}$ ). Following a further clean up with AMPure XP beads, the libraries were quantitated with a Bio-Analyser and 4 libraries were pooled at equal concentrations (200 ng each) for exome capture, which was repeated twice. For exome capture, Coding Exome Oligos were added to the pooled libraries together with Capture Target Buffer 3 and incubated for $95{ }^{\circ} \mathrm{C}$ for $10 \mathrm{~min}$ and 18 cycles of one minute incubations, starting at $94{ }^{\circ} \mathrm{C}$, then decreasing $2{ }^{\circ} \mathrm{C}$ per cycle with a final incubation for $58{ }^{\circ} \mathrm{C}$ for $90 \mathrm{~min}$. Immediately afterwards, the hybridized probes were captured with streptavidin magnetic beads for $25 \mathrm{~min}$ at RT and washed twice with Enrichment Wash Solution (incubation at $50{ }^{\circ} \mathrm{C}$ for $20 \mathrm{~min}$ ). Finally an Elution Premix was prepared with Enrichment Elution Buffer 1 and $\mathrm{NaOH}$. The streptavidin beads were resuspended in this Elution Premix, incubated for two minutes at RT, the supernatant was separated from the beads on a magnetic stand and Elute Target Buffer 2 was added to the supernatant. After the second exome capture, the libraries were cleaned up with AMPure XP beads. Finally, a second enrichment was performed with the Enhanced PCR Mix $\left(98^{\circ} \mathrm{C}\right.$ for $30 \mathrm{~s}$ followed by 10 cycles of $98^{\circ} \mathrm{C}$ for $10 \mathrm{~s}, 60^{\circ}$ $\mathrm{C}$ for $30 \mathrm{~s}$ and $72^{\circ} \mathrm{C}$ for $30 \mathrm{~s}$, with a final extension at $72^{\circ}$ $\mathrm{C}$ for $5 \mathrm{~min}$ ) and the amplified libraries were purified 
again with AMPure XP beads. Finally, quality control was performed with a Bioanalyser ${ }^{\circ}$ (Agilent).

\section{Reduced representation bisulfite sequencing (RRBS) library preparation}

Reduced representation bisulfite sequencing allows for highly accurate and efficient analysis of methylation patterns at single base pair resolution with a focus on $\mathrm{CpG}$ islands [21]. Digestion was performed with $2.5 \mu \mathrm{g}$ gDNA in buffer 4 (NEB) and 400 units MSPI O/N at $37{ }^{\circ} \mathrm{C}$. Afterwards, the DNA was purified from this reaction with the PCR purification Kit (Qiagen) according to the manufacturer's instructions. Briefly, 5 volumes buffer PB were added to the MSPI digest, applied to a spin column provided in the kit and centrifugation was performed for $1 \mathrm{~min}$ at $9500 \times g$. Then, the column was washed with $750 \mu \mathrm{l}$ buffer PE, dried by centrifugation for $1 \mathrm{~min}$ at $9500 \times g$ and the DNA was eluted with $30 \mu$ l buffer EB. Library preparation was then performed with the NEXTflex $^{\mathrm{TM}}$ Bisulfite Library Prep Kit (BIOO Scientific) according to the manufacturer's instructions with some modifications. Briefly, end repair was performed with 500 ng digested, purified DNA in end repair buffer mix and end repair enzyme mix in a total volume of $50 \mu \mathrm{l}$. The reaction was incubated at $22{ }^{\circ} \mathrm{C}$ for $30 \mathrm{~min}$ and then cleaned up with the MinElute ${ }^{\bullet}$ PCR Cleanup Kit. Then, $16.5 \mu \mathrm{l}$ of the eluate were mixed with $4.5 \mu \mathrm{l}$ of adenylation mix and the reaction was incubated for $30 \mathrm{~min}$ at $37{ }^{\circ} \mathrm{C}$. Afterwards, $31.5 \mu \mathrm{l}$ ligation mix and $2.5 \mu \mathrm{l}$ of individual adapters (diluted 1:2) were added, and adapter ligation was performed for $15^{\prime}$ at $22^{\circ} \mathrm{C}$. Afterwards, the DNA was cleaned with AMPure XP beads and size selection for fragments from 175 to $400 \mathrm{bp}$ was performed with a gel purification step. The libraries were separated on a $2 \%$ low melt agarose gel (Sigma-Aldrich), the cut out gel fragments were dissolved for $10 \mathrm{~min}$ at RT in DNA binding buffer and $150 \mu \mathrm{l}$ ethanol were added. Then, the solution was applied to a clean-up spin column and centrifuged at $18500 x g$ until the complete volume was processed. Afterwards, the column was washed twice with DNA wash buffer, dried by centrifugation and the DNA was eluted with column elution buffer. Then, bisulfite conversion of the DNA was performed with the EZ Methylation Gold Kit (Zymo Research) according to the manufacturer's instructions. Briefly, $130 \mu \mathrm{l}$ conversion reagent were added to $20 \mu \mathrm{l}$ purified DNA. The reaction was incubated for $10 \mathrm{~min}$ at $98{ }^{\circ} \mathrm{C}$ and for $2.5 \mathrm{~h}$ at $64{ }^{\circ} \mathrm{C}$. Then, the samples were loaded on spin columns containing $600 \mu \mathrm{l}$ M-Binding buffer and mixed by inverting. The DNA was bound to the column by centrifugation for $30 \mathrm{~s}$ at $18620 \times \mathrm{g}$. Then, the column was washed with $100 \mu \mathrm{l}$ wash buffer, and $200 \mu \mathrm{l}$ desulphonation buffer were added. The desulphonation buffer was incubated for $17 \mathrm{~min}$ at $\mathrm{RT}$, and then removed by centrifugation. The column was washed twice with $200 \mu \mathrm{l}$ wash buffer, and dried by centrifugation for $10 \mathrm{~s}$. Finally, $17 \mu$ l elution buffer were added to the column, incubated for $1 \mathrm{~min}$ and the DNA was eluted by centrifugation. Afterwards, PCR amplification of the bisulfite converted libraries was performed with PfuCx Hot Start (Agilent). $15 \mu \mathrm{l}$ DNA were amplified with the NEXTflex ${ }^{\mathrm{Tm}}$ Primer Mix. Cycling conditions were: Initial denaturation for five minutes at $95{ }^{\circ} \mathrm{C}$. Then 18 cycles of $95{ }^{\circ} \mathrm{C}$ for $30 \mathrm{~s}, 65{ }^{\circ} \mathrm{C}$ for $30 \mathrm{~s}$ and $72{ }^{\circ} \mathrm{C}$ for $45 \mathrm{~s}$. Afterwards a final extension at $72{ }^{\circ} \mathrm{C}$ for $7 \mathrm{~min}$. The libraries were purified again using AMPure XP beads (Beckmann Coulter). Finally, quality control with a Bioanalyser ${ }^{\bullet}$ (Agilent) was performed.

\section{Small RNA library preparation}

Small RNA libraries were prepared from $1 \mu \mathrm{g}$ total RNA containing small RNAs with the TrueSeq Small RNA kit (Illumina) according to the manufacturer's instructions. Briefly, a 3'adapter was added to the RNA, denaturation was performed for two minutes at $70{ }^{\circ} \mathrm{C}$ and afterwards the mixture was put on ice immediately. Then, the adapter was ligated with a T4 RNA Ligase2 deletion mutant (epicentre) for $1 \mathrm{~h}$ at $28{ }^{\circ} \mathrm{C}$. Then the reaction was stopped with stop solution for $15 \mathrm{~min}$ at $28{ }^{\circ} \mathrm{C}$, the previously denatured 5 ' adapter was added together with ATP and T4 DNA Ligase and ligated to the RNA for $1 \mathrm{~h}$ at $28{ }^{\circ} \mathrm{C}$. After that, cDNA synthesis was performed with super script II and Illumina supplied dNTPs for $1 \mathrm{~h}$ at $50{ }^{\circ} \mathrm{C}$. Afterwards, the cDNA was amplified and indexed with the primers and PCR mix supplied in the kit (eleven cycles of denaturation at $98{ }^{\circ} \mathrm{C}$ for $10 \mathrm{~s}$, annealing $60{ }^{\circ} \mathrm{C}$ for $30 \mathrm{~s}$ and extension at $72{ }^{\circ} \mathrm{C}$ for $15 \mathrm{~s}$ with a final extension at 72 for $10 \mathrm{~min}$ ) and size selection was performed on $5 \% \mathrm{TBE}$ acrylamide gels (Bio-Rad, Munich, Germany). Here, the region marked by Illumina's custom ladder between $145 \mathrm{bp}$ and $160 \mathrm{bp}$ were cut out and pooled for sequencing. The gel was homogenized by centrifugation at $20000 \times g$ through a gel breaker tube (Bio-Cat) and $300 \mu \mathrm{l}$ ultrapure $\mathrm{H}_{2} \mathrm{O}$ were added to elute the DNA O/ $\mathrm{N}$ in a DNA LoBind tube (Eppendorf). The following day, the gel debris was separated from the water by centrifugation for $10 \mathrm{~s}$ at $600 x g$ through a $5 \mu \mathrm{m}$ filter tube (Bio-Cat). Then, $2 \mu$ glycogen (CALBIOCHEM), $30 \mu \mathrm{l}$ sodium acetate (Thermo-Fisher Scientific), $2 \mu \mathrm{l}$ $0.1 \times$ pellet paint and $975 \mu \mathrm{l}$ prechilled $100 \%$ ethanol were added and the mixture was incubated for $20 \mathrm{~min}$ at $-80{ }^{\circ} \mathrm{C}$. Then, the library was pelleted by centrifugation for $20 \mathrm{~min}$ at $4{ }^{\circ} \mathrm{C}$ and $20,000 \mathrm{xg}$, washed with $70 \%$ ethanol and recentrifuged for $5 \mathrm{~min}$. Finally, the ethanol was removed, the pellet dried for five minutes at $37{ }^{\circ} \mathrm{C}$ and resuspended in $15 \mu$ l ultrapure water. 


\section{Next-generation sequencing}

Illumina deep sequencing as well as quantification of small RNA content were performed at a genomics core facility: Center of Excellence for Fluorescent Bioanalytics (KFB, University of Regensburg, Germany). For deep sequencing, all libraries were quantified using the KAPA SYBR FAST ABI Prism Library Quantification Kit (Kapa Biosystems, Woburn, MA, USA). Equimolar amounts of each library were used for cluster generation on the cBot with the TruSeq SR Cluster Kit v3 (Illumina, San Diego, CA, USA). The sequencing run was performed on a HiSeq 1000 instrument (Illumina, San Diego, CA, USA) using the indexed, 50 cycles single read (SR) protocol and the TruSeq SBS v3 Kit (Illumina, San Diego, CA, USA). Image analysis and base calling resulted in .bcl files which were then converted into fastq files by the CASAVA1.8.2 software.

\section{Data analysis for (small) RNA libraries}

Analysis of poly-A RNA, RNA enriched with the coding exome oligos and small RNA data was performed using the Genomatix software (Genomatix, Munich, Germany). For poly-A RNA and RNA enriched with the coding exome oligos, the fastq files were mapped to the human genome assembly GRCh38 (annotation based on ElDorado 6-2015) using the Genomatix Mining Station Mapper v3.7.6.3 allowing one mismatch. We sequenced all poly-A RNA libraries until at least $15 * 10^{6}$ and all exome capture libraries until at least $10 \times 10^{6}$ unique hits per sample could be mapped. All unique hits were further processed using the Genomatix Genome Analyser v3.51106 which was used to create count tables and RPKM expression values for all samples. Reads were counted locus-based, i.e. for unions of exons of genes. All further analyses based on these count tables were performed with the free software R v3.1.1, Bioconductor v3.0 [20] and the package DESeq2 v1.6.3 [36]. Gene set enrichment analysis [53] was performed with GenePattern and the GSEA module v18 [53] with RPKM (reads per kilobase of exon model per million mapped reads) values and gene sets c2.Biocarta as well as c2.KEGG using standard settings. For small RNA analysis, we mapped fastq files against a small RNA library based on GRCh38 (annotation based on ElDorado 6-2015) allowing one mismatch. Afterwards, count tables were created for each small RNA type (piRNA, mature miRNA, miRNA hairpin structures) with the small RNA workflow available in the Genomatix Genome Analyser. We sequenced all samples until at least $1 \times 10^{6}$ counts for mature miRNAs were reached when reads were counted, with a mean of unique hits for mature miRNAs of $3,037,413 \pm 2088,481$ and for piRNA 9,754,231 $\pm 4,096,709$. All further single locus based analyses were performed as described for poly-A RNA. For further analysis of piRNAs, we matched the RNAdb2.0 identifiers [45], on which Genomatix is based, to the pIRbase [66], which provides information on the genomic localization, sequence as well as the elements from which the respective piRNAs are derived. Parts of the poly-A RNA-Seq dataset were generated in a collaborative project and three poly-A RNA-Seq runs from neurons are also contained/analysed in [59].

\section{RRBS analysis}

For RRBS, fastq files were trimmed with TRIM Galore v0.4.2 in the rrbs mode and mapped with BISMARK v0.16.3 [28] to the human genome GRCh38.84 as obtained from www.ensembl.org. Then, the methylation values were extracted with the BISMARK methylation extractor again removing $2 \mathrm{bp}$ at the five prime end of the reads to remove the methylation bias in untrimmed reads stemming from the end repair procedure. We sequenced the libraries until at least $1 \times 10^{6}$ alignments with a unique best hit were found by BISMARK. All further analyses were performed based on extracted coverage files with RnBeads v1.2.0 [4].

\section{Data availability}

All normalized NGS data were deposited in GEO (URL: https://www.ncbi.nlm.nih.gov/geo) under the super series accession GSE110720. Coding exome RNA-Seq data is deposited under accession GSE110716, Poly-A RNA-Seq data is deposited under accession GSE110717, RRBS data is deposited under accession GSE110718 and small RNA-Seq data under accession GSE110719.

\section{Quality control and inclusion criteria}

Due to historical reasons, the mRNA data for quality control analyses of iPSCs were mapped to the human genome GRCh37 without mismatch. We included all samples that we analysed, as long as they met the following criteria: iPSCs had to show a marker expression of the pluripotency markers DNMT3B, SOX2, NANOG, OCT4 and REX1 within the range of a previously analysed high quality ESC cohort and to fall at least in the safety margin of a previously established database driven PluriTest adaption [57]. Furthermore, viral transgene silencing had to be comparable to a published cohort for which NGS raw data was freely available [1]. We analysed viral transgene silencing both by comparison of RPKM values of established markers of viral transgene silencing [27] as well as by direct mapping of the plasmids used for reprogramming counting multiple and unique hits when mapping against the vector sequence (excluding the coding regions of the pluripotency factors) normalized to the number of unique hits of the respective sequencing run when mapped to the genome. The upper-limit cut-offs shown in the supplementary material were calculated as described in [57]. SNPs were 
called within the Genomatix Genome analyser with a workflow based on samtools, with at least $4 \mathrm{x}$ coverage per SNP and exclusion of indels. We excluded five iPSC lines based on these criteria.

Patient samples, tissue samples and embryonic stem cells The Institutional Review Board approval (Nr. 4120: Generierung von humanen neuronalen Modellen bei neurodegenerativen Erkrankungen) and informed consent forms are on file at the movement disorder clinic at the Department of Molecular Neurology, Universitätsklinikum Erlangen (Erlangen, Germany). All procedures involving patient samples (tissues or cells) were approved by the local institutional review board (Ethikkommission Regensburg), approval 14-101-0216. The experiments involving embryonic stem cells were approved by the Central Ethics Committee for Stem Cell Research in Germany according to StZG (AZ: 3.04.02/0121). Tissue samples were obtained from the Netherlands brain bank as fresh frozen tissue. iPSCs were generated from skin biopsies of PD- and control-patients by the ForIPS core project as described elsewhere [15].

\section{Immunohistochemistry}

The presence of Lewy bodies in the substantia nigra and more importantly in the cingulum was verified with stained sections from the Netherlands brain bank (NBB). For those cases were no staining was available, we obtained paraffin sections from the NBB and performed a staining with an antibody directed against aggregated $\alpha$-synuclein (anti-human $\alpha$-synuclein 5G4, mouse monoclonal, analytikjena, Jena, Germany). After deparaffinization, antigen retrieval was performed by cooking in citrate buffer for $20 \mathrm{~min}$ and $\mathrm{DAB}$ staining was performed with the Envision Dual Link System-HRP DAB+ Kit (Agilent, Santa Clara, CA, USA) according to the manufacturer's instructions. Briefly, the sections were blocked with Dual Endogenous Enzyme Block for 10 min and rinsed with PBS. Then, primary antibody was applied (diluted 1:500 in PBS + 1\% BSA) for $40 \mathrm{~min}$ and again the slides were washed with PBS. Afterwards, labelled polymer was added for $30 \mathrm{~min}$. After a further washing step, substrate was added for five minutes. Afterwards, the slides were washed in running tap water, counterstained in hemalaun (Dako/Agilent) and again rinsed in running tap water. Finally, the slides were dehydrated in increasing ethanol concentrations and $x y-$ lol and mounted in entellan mounting medium (Merck).

\section{Methyl-cytosine staining}

For analysis of methyl-cytosine content in tissue, we cut frozen tissue sections from the cingulate gyrus material. The DAB staining was performed with the Envision Dual Link System-HRP DAB+ Kit (Agilent, Santa Clara, CA,
USA) according to the manufacturer's instructions with some modifications. After cutting and thawing, the sections were first fixed with 4\% PFA for $15 \mathrm{~min}$, which was necessary as we retrieved unfixed material. Then the sections were washed three times for five minutes in TBS. Afterwards, the slides were incubated for $30 \mathrm{~min}$ in $2 \mathrm{~N}$ $\mathrm{HCl}$ for antigen retrieval. The slides were washed twice with PBS and blocking was performed with the Dual Endogenous Enzyme Block reagent for $10 \mathrm{~min}$ at RT. After further washing in TBS, anti-methyl-cytosine (Epigentek, mouse monoclonal, clone 33D3) antibody was added in 1:400 dilution and incubated $\mathrm{O} / \mathrm{N}$ at $4{ }^{\circ} \mathrm{C}$ in $1 \%$ normal goat serum (PAN Biotech, Aidenbach, Germany) in TBS $+0.3 \%$ TritonX. A mouse IgG (Thermo-Fisher) was used as negative control. The next day, the slides were washed three times, covered with labelled polymer and incubated for $30 \mathrm{~min}$ at RT. Then, after one washing with TBS, the sections were covered with chromogen for $10 \mathrm{~min}$. Afterwards, the slides were washed in running tap water, counterstained in Mayer's hemalaun and again rinsed in running tap water. Finally, the slides were dehydrated in increasing ethanol concentrations and xylol (Carl-Roth) and mounted in entellan mounting medium (Merck).

\section{CDNA synthesis, real-time PCR and semiquantitative PCR} cDNA synthesis was performed from 200 ng total RNA using random hexamer primers (Gene Link, Hawthorne, NY, USA) and the SuperScript ${ }^{\mathrm{ma}}$ II Reverse Transcriptase (Life Technologies) according to the manufacturer's instructions. Real-time RT-PCR was performed with the SensiFAST $^{\text {ma }}$ SYBR Hi-Rox Kit (Bioline, London, UK) on the StepOnePlus ${ }^{\text {Tix }}$ cycler (Life Technologies). Relative expression values were calculated with the $\Delta \Delta \mathrm{C}_{\mathrm{T}}$ (analysis of relative gene expression) method [35] using $A R F-1$ as the reference transcript. Primers used for $A R F-1$ were 5'-GACCACGATCCTCTACAAGC (forward) and 5'-TCCCACACAGTGAAGCTGATG (reverse), for $T H$ 5'-CCAAGACCAGACGTACCAGT (forward) and 5' CGTGAGGCATAGCTCCTGAG (reverse). Primers for analysis of SYP, MAP2, TUBB3, EN1, NURR1, KCNJ6 and FOXA2 were described by others [34]. Primers for WNT3 5'-GGAGAGGGACCTGGTCTACTA (forward) and 5' CTTGTGCCAAAGGAACCCGT (reverse) were and downloaded from the PrimerBank database [63]. Analysis of mtDNA content was performed with the real-time PCR conditions as described above and primers for mtDNA and nuclear DNA as described by others [51], as was analysis of mtDNA deletions [11]. Semiquantitative PCR was performed with the HotStarTaq polymerase (Qiagen) according to the manufacturer's instructions and the equivalent of 125 ng cDNA per reaction. An annealing temperature of $55{ }^{\circ} \mathrm{C}$ and 35 cycles were used for amplification. Primers for semiquantitative PCR were designed with Primer3Plus [61]. 
Primer sequences for PIWIL2 were 5'-TTGGATTCG AAAATGGCTTC (forward) and 5'-AGCCAGGAA GCGGTTATTTT (reverse), PIWIL4 5'-CAAGGACGT GATGGTTGTTG (forward) and 5'-ACCGACAGT CTTGAGCTGGT (reverse). GAPDH was used as reference with the primers 5 -CCATCTTCCAGGAGCGAGAT (forward) and 5'-ATGATGTTCTGGAGAGCCCC (reverse).

\section{Statistics}

All statistical analyses of NGS data were performed with the software packages described above and standard settings, unless otherwise indicated. A (small-) RNA locus was defined as differentially regulated when it was deregulated at a $\log 2 \mathrm{FC}$ of $\geq 0.6$ and an adjusted $p$-value of $<0.1$. For analysis of methylation data a cytosine was accepted as differentially methylated when it passed the threshold $\Delta$-meth $\geq 0.2$ and an adjusted $p$-value of $<0.1$.
A gene set was accepted as differentially enriched at a $p$-value $<0.05$ and a false discovery rate $(\mathrm{FDR})<0.25$. Otherwise, all statistical tests used are provided in the figure legends and the results part together with the sample size. All bar graphs show the mean + standard deviation (SD) unless otherwise indicated.

\section{Results}

\section{Patient recruitment, cell line establishment and quality} control

We gained skin fibroblasts from six healthy control- and nine sporadic Parkinson's disease (PD)-patients within the Bavarian Research Network Induced Pluripotent Stem Cells (ForIPS). All samples were derived from inner upper arm skin biopsy derived fibroblasts. Early passage fibroblast samples were reprogrammed to iPSCs using retroviral reprogramming Yamanaka factors. From all except one patient (PD7) iPSC lines were established,

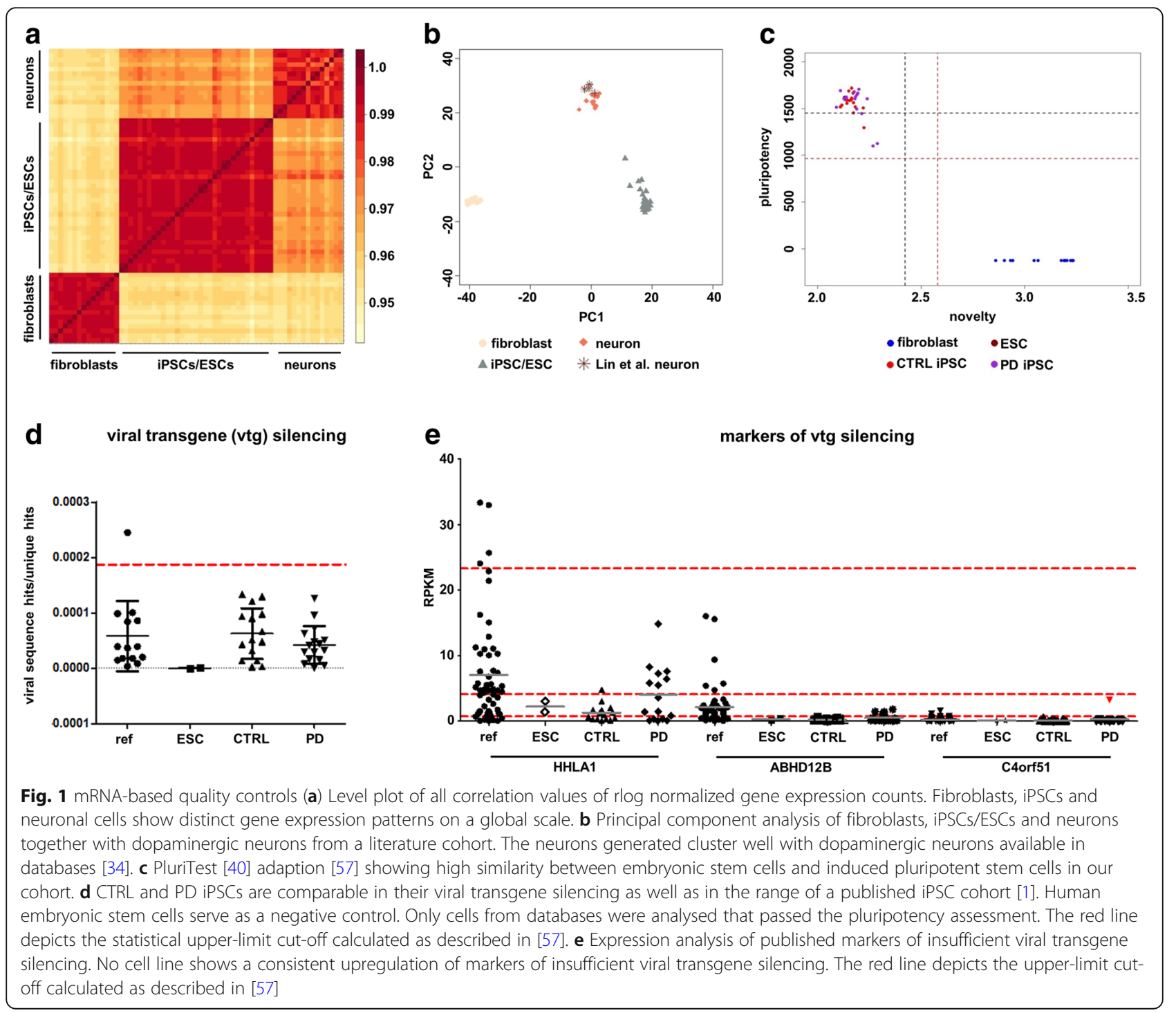


and finally a subset of these lines was further differentiated to midbrain neurons (MN) (Additional file 1: Table S1 for details on the patient cohort).

Analysis of the transcriptome showed that fibroblasts, iPSCs and differentiated neuronal cells -as expectedhad globally distinct gene expression patterns (Fig. 1a). Our neurons clustered well in a principal component analysis with dopaminergic neurons published by others [34] (Fig. 1b). We then validated that all iPSCs corresponded to high quality pluripotent cells according to our recent PluriTest adaption for NGS [57] (Fig. 1c). This means that all cell preparations mapped at least within a calculated statistical cut-off, with most preparations also meeting the requirements of an empirical cut-off of high quality pluripotent cells (for further information see [57]). We checked for the expression of pluripotency marker genes (in the range of high quality pluripotent cells, Additional file 2: Figure S1), ensured that cells showed viral transgene silencing (examined by direct mapping to the vector sequences used for reprogramming) and excluded that markers of insufficient viral transgene silencing were overexpressed [27] (Fig. $1 \mathrm{~d}$ and e). In addition, we performed a SNP based paternity testing for every reprogrammed and differentiated line. All cell lines used for further analyses met these stringent quality criteria.

The neuronal cells showed robust induction of the dopaminergic neuron marker $\mathrm{TH}$, and there was no significant difference between the control- and PD-group in the expression of TH, EN1, MAP2, FOXA2, KCNJ6, SYP2, TUBB3 and NURR1 (two-sided Mann-Whitney test, $p>0.05$ for all comparisons, $n=8$ CTRL and 7 PD derived MN neurons, Additional file 3: Figure S2). In addition the cells were not showing morphological differences or increased cell death without stressor [59] as has been described for genetic models of the disease [42, 53].

\section{Disease-specific phenotypes in differentiated neurons on mRNA level}

A hierarchical clustering based on mRNA data (TOP2000 variable genes, rlog-normalized) clustered the samples by cell type, but no distinct groups were detected for PD- and control-patient derived cells (Fig. 2a). We then went on to examine differential gene expression between control- and PD-derived cell populations within every cell type and adjusted our model for differential expression for the covariate gender and for the iPSCs additionally for passage number. As ageing marks have been reported to be removed in four-factor reprogrammed cells [39], we did not include age as a covariate in the analysis of iPSCs and differentiated neurons, but only for fibroblasts.
It became evident that relevant differential gene expression between the PD- and control-group could only be observed in neuronal cells with 97 deregulated loci, but not in fibroblasts with 3 or iPSCs with 11 deregulated $\operatorname{loci}(\log 2 \mathrm{FC} \geq 0.6$, p-adj. $<0.1$, Fig. $2 \mathrm{~b}$ and Additional file 4: Table S2). Analysing these alterations in neuronal cells on the single gene level, genes that belong to the WNT-pathway were deregulated, i.e. WNT3 was upregulated in PD-patient derived neurons (two-sided Mann-Whitney test, $p<0.05, n=8$ CTRL neurons and 7 PD neurons, Fig. 2c). On the pathway level, the NOS1and CREB-pathways as well as the pathway regulating PGC1 $\alpha$ (among others) were significantly inactivated in PD-patient derived neurons $(p<0.05, \mathrm{FDR}<0.25, \mathrm{n}=8$ CTRL neurons and 7 PD neurons, Figs. $2 \mathrm{~d}$ and e and Additional file 5: Table S3). Both, the PGC1 $\alpha$ - and CREB-pathway are well-known and important regulators of neuronal cell survival $[23,67]$. As such, these findings provided first implications for the usefulness of neuronal models derived from sporadic PD-patients via the iPSC stage for disease modelling and prompted us to further examine the epigenome of our cell lines across differentiation stages.

\section{A disease-specific piRNA/piRNA-like molecule signature is present across all differentiation stages}

Next, we examined the small RNA expression patterns via NGS in all 15 fibroblast cell lines, 24 iPSC lines, two hESC lines and ten lines differentiated to midbrain neurons. When PD-patient derived cells were compared with controls, there were 26 deregulated miRNAs in fibroblasts, 34 in iPSCs and 40 in neurons (p-adj $<0.1$, $\log \mathrm{FC} \geq 0.6$, Additional file 6: Figure S3A and Additional file 7: Table S4). For mature miRNAs, the first important finding was that let-7 family members are upregulated in PD-patient derived neurons (Additional file 6: Figure S3B). The let-7 family has been reported to be deregulated in a C. elegans model of PD [3] and this might be another regenerative mechanism, like WNT-pathway upregulation, in PD-derived neurons.

Even more strikingly, we found a high number of PIWI interacting RNAs (piRNAs) differentially regulated in all cell populations (Fig. 3a and Additional file 8: Table S5). We next checked if genes that control piRNA biogenesis are actually expressed in cultured neurons. Indeed, PIWIL2 and PIWIL4 expression were detectable in cultured midbrain neurons (Fig. 3b) which is similar to results that others have published from tissue in mouse [41] and human [60]. Importantly, when we examined all 15 fibroblast lines and a subset of 13 PD iPSC and 10 control iPSC lines as well as two hESC lines for total small RNA content, there were no significant differences (Kruskall-Wallis test, $p>0.05$, Additional file 9: Figure S4A). We also asked if our library preparation 


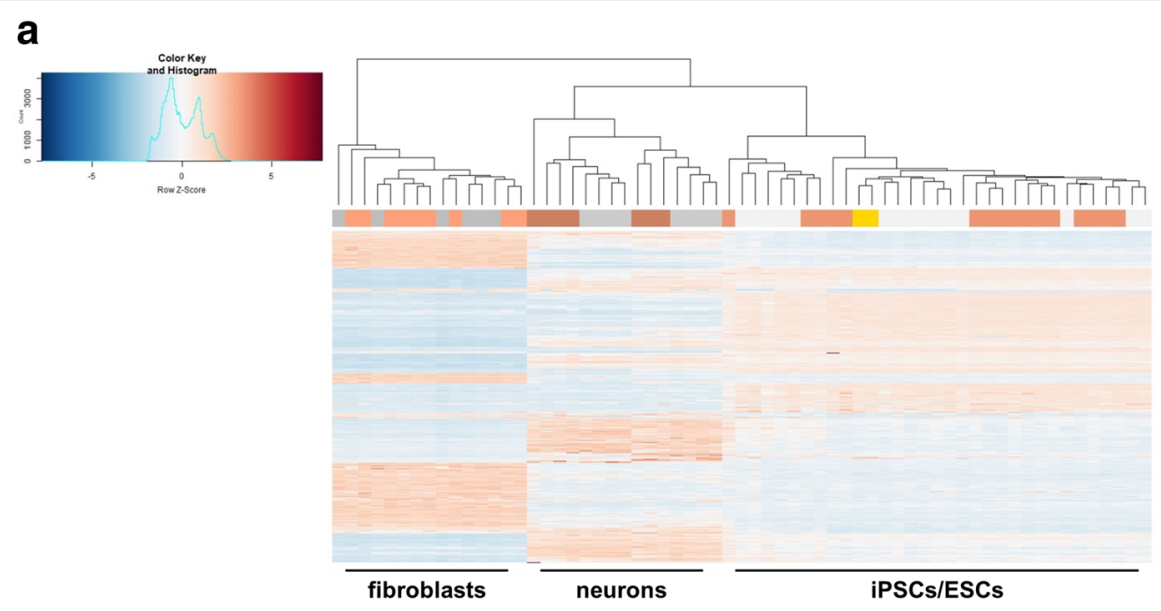

b

\begin{tabular}{|c|c|}
\hline Differential expression ( $p$-adj. $<0.1$ and $\log 2 F C \geq 0.6)$ \\
\hline cell type & $\begin{array}{c}\text { number of deregulated } \\
\text { genes }\end{array}$ \\
\hline fibroblasts ( $\mathbf{n}=\mathbf{1 5})$ & $\downarrow 2 \uparrow 1$ \\
\hline iPSCs/ESCs ( $\mathbf{n = 3 3 )}$ & $\downarrow 3 \uparrow 8$ \\
\hline neurons ( $\mathbf{n = 1 5})$ & $\downarrow 45 \uparrow 52$ \\
\hline
\end{tabular}

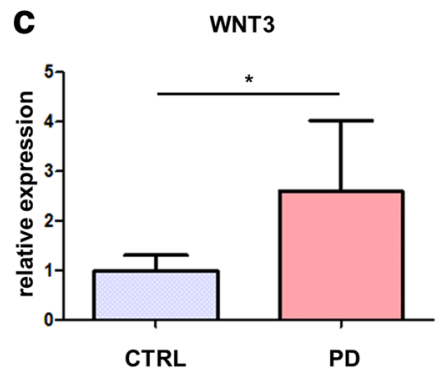

d

e

\section{CREB}

$(p=0.008, F D R=0.122)$

PGC1a

$(p=0.044, F D R=0.159)$

NOS1 $\downarrow(p=0.010, F D R=0.104)$

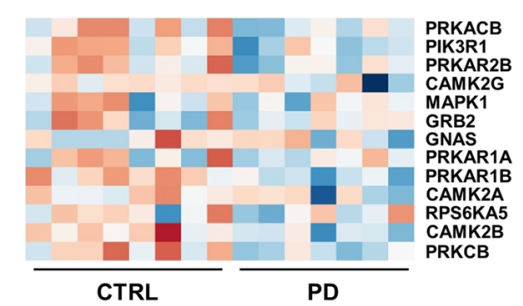

Fig. 2 mRNA expression profiling of PD-patient derived cell lines (a) Heatmap and hierarchical clustering based on the TOP2000 variable genes on mRNA expression data. Hierarchical clustering separates the samples by cell type (fibroblast, iPSC/ESC or neuron). PD-patient derived cells (shades of salmon) are not separated from control-patient derived cells (shades of grey) and iPSCs are not separated from ESCs (gold). $\mathbf{b}$ Summary of differential expression analysis results as calculated by DESeq2 between control- and PD-patient derived cells. A significant number of deregulated genes is only present in neurons, but not in fibroblasts or iPSCs. c WNT3 is differentially expressed between control- and PDpatient derived cells as judged by real-time PCR (two-sided Mann-Whitney test, $p<0.05$ ). Shown are means + SD. $\mathbf{d}$ The NOS1- and CREBpathways as well as the pathway regulating PGC1a (as defined by c2.Biocarta) are significantly inactivated in PD-patient derived neuronal cells ( $p$ $<0.05$ and FDR $<0.25$ as calculated by GSEA). e Heatmap of CREB pathway genes that show a core enrichment in the GSEA analysis based on rlog normalised expression values of the midbrain neurons

included the correct length fraction of piRNAs. With our library preparation protocol, we expect the 2432 bp piRNAs to run approximately between 150 and $160 \mathrm{bp}$, slightly higher than $22 \mathrm{bp}$ mature miRNAs. The library sizes of small RNA libraries showed peaks in this size range (Additional file 9: Figure S4B). Of course, it should be noted that other RNA species, e.g. iso-mirs can also be present in these higher size ranges. As contamination of piRNAs with other RNAs, i.e. snoRNA degradation products has been a concern for IP based approaches [49], we checked the overlap between the piRNA sequences we used for piRNA mapping [66] and a snoRNA database [32]. However, as the overlap with snoRNAs was negligible and as the piRNAs identified by us showed the typical 5-prime Uridine bias, we conclude that we identified bona fide piRNA sequences. Nonetheless, as a length of 24-32 bp is another important criterion for canonical piRNAs [68] we checked the length 


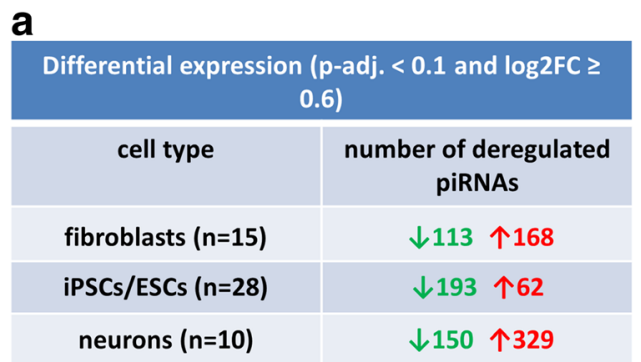

C
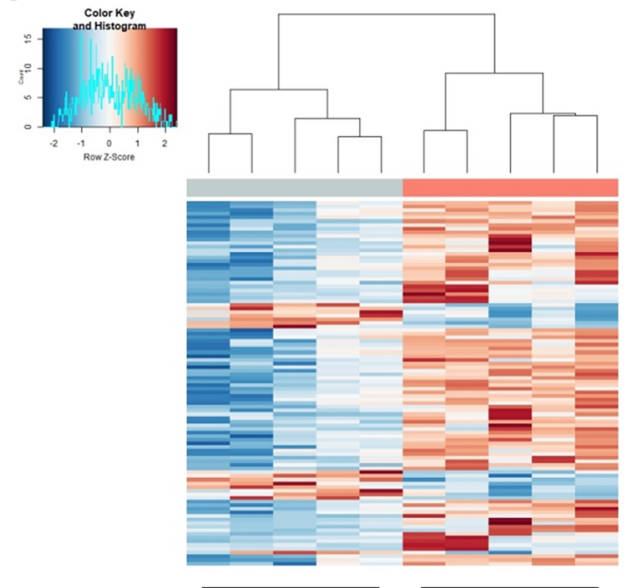

CTRL

PD

\section{e}

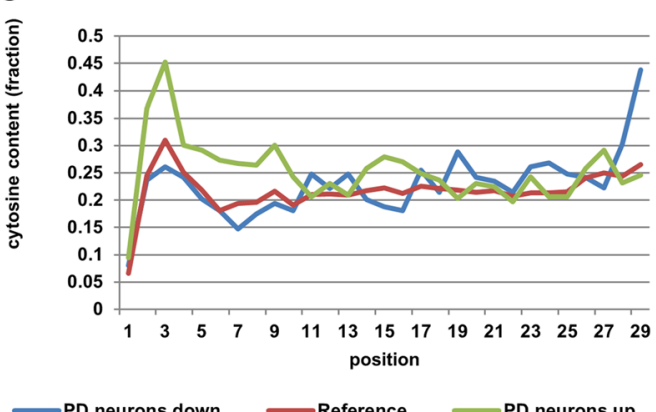

b

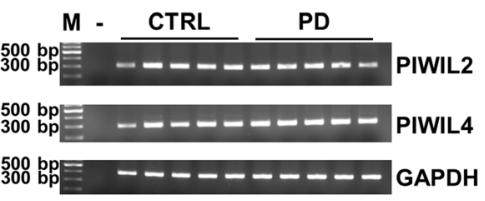

d

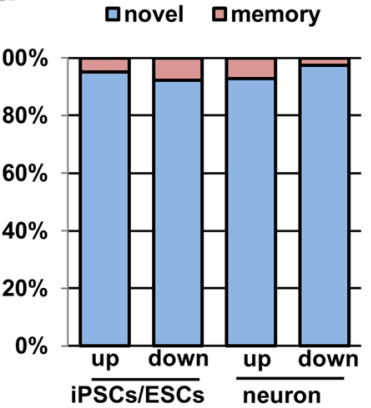

$\mathbf{f}$

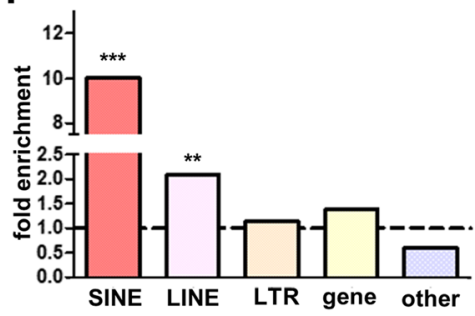

Fig. 3 piRNAs are differentially expressed between control- and PD-patient derived cells (a) Differentially expressed piRNAs between control- and PD-patient derived cells (log2FC $\geq 0.6, \mathrm{p}$-adj. < 0.1) in fibroblasts, iPSCS/ESCs and neurons. $\mathbf{b}$ Semiquantitative PCR of PIWIL2 and PIWIL4 in the neurons used for the analysis of small RNA expression patterns. Both genes are expressed in cultured neurons. GAPDH was used as a loading control. A 100 bp DNA-ladder (M) and a negative control (-) were loaded together with the PCRs from control (CTRL) and PD-patient (PD) neuronal samples. c Heatmap and hierarchical clustering based on the TOP100 differentially expressed piRNAs in neurons (sorted by adjusted pvalue). PD-patient derived cells (salmon) are clearly separated from control-patient derived cells (azure). $\mathbf{d}$ Memory-related piRNAs (i.e. piRNAs already differentially expressed in parental fibroblasts) are present, but constitute a minor fraction $(<10 \%)$ of all deregulated piRNAs in iPSCs/ESCS and neurons. e Plot of cytosine content in all deregulated piRNAs over nucleotide positions 1 to 29. In the first 10 nucleotides, cytosines are overrepresented in the upregulated piRNAs (green line) as compared to all piRNAs analysed (dark red line). This observation does not apply to the downregulated piRNAs (blue line). $\mathbf{f}$ SINE- and LINE-derived piRNAs are highly enriched in the downregulated piRNA fraction in neurons. SINE- and LINE-derived piRNAs (but not LTR- or gene-derived piRNAs) are significantly enriched in the fraction of downregulated piRNAs as compared to their abundance in the genome (two-sided chi-square test, $p<0.0001$ and $p<0.01$, respectively)

fractions of our sequenced libraries after adapter trimming (data not shown). Due to the fact that there were less reads in the range of 24-32 bp than unique piRNA hits, we conclude that our dataset contains canonical piRNAs and piRNA-like molecules that are abundantly expressed outside of the testes as has been described by others [64]. For simplicity, piRNAs and piRNA-like molecules are referred to as piRNAs in the rest of the manuscript.

Based on the TOP100 significantly deregulated piRNAs, PD- and control midbrain neurons formed 
separate clusters in a hierarchical clustering analysis (Fig. 3c). However, the fraction of memory piRNAs (i.e. piRNAs that were differentially regulated between PDand control-patient derived iPSCs/neurons and already found deregulated in fibroblasts) was rather low and always below $10 \%$ of all deregulated piRNAs (Fig. 3d). Only two piRNAs, piR-48,442 and piR-43,518, were deregulated between PD- and control-patients across all cell types (Additional file 8: Table S5).

Among the upregulated piRNAs, there was a strong enrichment of cytosine content within the bases two to nine of the piRNAs as compared to the reference of all piRNAs (Fig. 3e).

We then analysed with the annotations provided in the piRBase [66] from which elements the deregulated piRNAs were derived. Interestingly, SINE- and LINE-derived piRNAs were significantly enriched among the downregulated piRNAs as compared to the genome-wide abundance of all piRNAs analysed in our study (two-sided chi-square test, $p<0.0001$ and $p<0.01$, respectively, Fig. 3f). Despite massive piRNA deregulation, however, we could not find any overlap between known PD-risk loci and predicted piRNA loci in the human genome (data not shown).

We conclude that -dependent on the cell type analysed- the aberrant small RNAome is activated at different differentiation stages but only few deregulated piRNAs are shared between these stages.

\section{piRNA expression differences in differentiation}

As there were striking differences in piRNA expression between PD- and control-patient derived cells, we hypothesized that piRNAs should be altered by neural induction in control cells, too. Indeed, piRNAs underwent dramatic changes after induction of pluripotency and neural differentiation and were even more dynamically regulated as mature miRNAs (Fig. 4a and Additional file 10: Table S6). As many piRNAs showed a low individual abundance, we checked the 20 most abundant and differentially expressed $(\operatorname{logFC} \geq 0.6$ and p-adj. $<0.1)$ and therefore potentially most important piRNAs in the comparison iPSC vs. neuronal cells that constitute on average $19.33 \pm 7.49 \%$ (mean \pm SD) of all piRNA counts across neurons and iPSCs (Fig. 4b). Importantly, among all deregulated piRNAs, again SINE-derived piRNAs were overrepresented in the comparison fibroblasts $(n=6)$ vs. iPSCs/ESCs $(n=16)$ and iPSC/ESC vs. neurons $(n=5)$ (two-sided chi-square test, $p<0.001$ and $p<0.0001$, respectively, Fig. 4c). As expected, a hierarchical clustering based on the TOP100 differentially expressed piRNAs separated control-patient derived neurons and iPSCs (Fig. 4d).

\section{Tissue validation of mRNA and mi/piRNA expression patterns}

For the evaluation of small RNA expression pattern in PD tissue, we used material from the cingulate gyrus of eight healthy and eight Parkinson's disease patients. We verified that the PD-patient derived tissues from the cingulate gyrus were positive for Lewy bodies (Fig. 5a). When analysing differential gene expression, we realized that oligodendrocyte marker genes were overrepresented in control patients, despite of the fact that classical cell type markers (GFAP, OLIG1/2/3, TUBB3 and RBFOX3) remained unchanged. We therefore included neuronal content (calculated as described in material and methods) as a covariate. A decreased transcriptional contribution of the oligodendrocyte lineage in Parkinson's patients had been reported previously [22]. Importantly, the mean RPKM of the marker gene sets reported by others in mouse [6] was very specific for human cells and neuronal and glial markers were highly correlated (Additional file 11: Figure S5).

With correction for cell type abundance, there were many deregulated small RNAs at $\operatorname{logFC} \geq 0.6$, p-adj. $p<0.1$ between PD- and control-patients (Fig. 5b and Additional file 12: Table S7). In our cohort, four miRNAs overlapped between tissue and neurons when control- and PD-patient derived cells were compared (Fig. 5c). As we found many deregulated piRNAs in neurons, we tested if there is expression of PIWIL2 and PIWIL4. Indeed, expression of both genes was detectable in all tissue samples (Fig. 5d).

In addition, there was abundant deregulation of piRNAs, effectively separating PD and control cases based on the TOP100 differentially expressed piRNAs (sorted by adjusted $p$-value, Fig. 6a). Although -as expected- differentially expressed piRNAs were largely different between cultured cells and tissues, there was an overlap of 70 piRNAs that deserve future evaluation as diagnostic marker (Fig. 6b). We again observed an overrepresentation of cytosines among the upregulated piRNAs in the second to ninth base (Fig. 6c). Importantly, both SINE- and LINE-derived piRNAs were enriched among the downregulated piRNAs in tissue, as was described for neurons above, although this reached significance only for LINE-derived elements (two-sided chi-square test, $p<0.05$, Fig. $6 \mathrm{~d}$ ).

Of note, enrichment of cytosines within the first $10 \mathrm{bp}$ and overrepresentation of SINE- and LINE-derived elements among the downregulated piRNAs was not consistently retained in fibroblasts and iPSCs. Therefore, aberrant piRNA expression is unmasked in differentiated neurons, but there is no significant epigenetic memory present within the small RNA fraction.

Only cell type specific differences exist in CpG methylation We then examined differential methylation between control and PD cell lines. We successfully sequenced 
a

\begin{tabular}{|c|c|c|}
\hline \multicolumn{3}{|c|}{ Differential expression ( $p$-adj. $<0.1$ and $\log 2 \mathrm{FC} \geq 0.6$ ) } \\
\hline small RNA type & fibroblast - iPSCs/ESCs & iPSCs/ESCs - neuron \\
\hline mature & $\downarrow 469$ & $\downarrow 412$ \\
\hline miRNA & $\uparrow 666$ & $\uparrow 460$ \\
\hline piRNA/piRNA-like & $\downarrow 2507$ & $\downarrow 1751$ \\
molecules & $\uparrow 2085$ & $\uparrow 1809$ \\
\hline
\end{tabular}

b

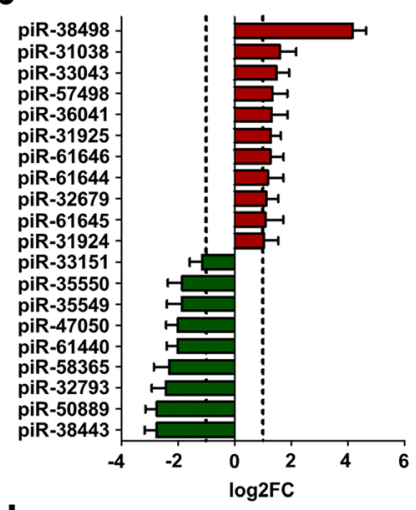

C

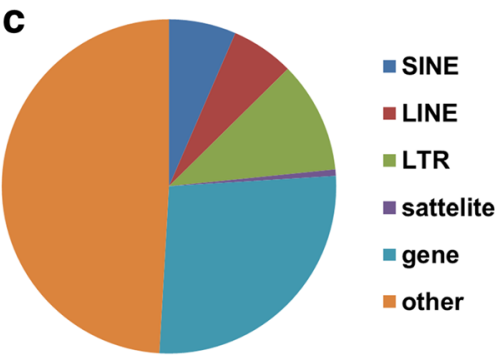

d
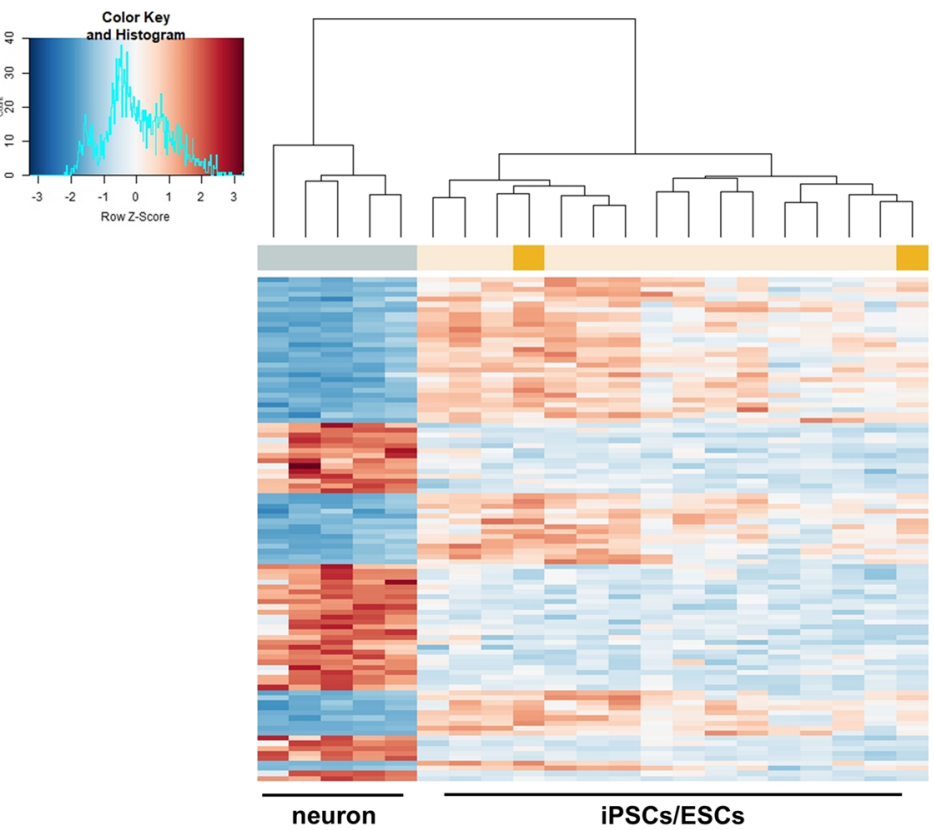

Fig. 4 piRNAs are differentially expressed during induction of pluripotency and neuronal differentiation. a Analysis of differential mature miRNA and piRNA expression by DESeq2 in control-patient derived cells. During induction of pluripotency and neuronal differentiation, piRNAs are as dynamically regulated as mature miRNAs. b TOP20 most highly expressed (sorted by base mean as calculated by DESeq2) and differentially regulated piRNAs in the comparison iPSC/ESC vs. neuron in control-patient derived cells. c Pie chart of the genomic elements from which the differentially regulated piRNAs in the comparison iPSC/ESC vs. neuron are derived. SINE-derived piRNAs are significantly enriched in the fraction of deregulated piRNAs as compared to their genome-wide abundance among all piRNAs annotated by piRBase, which is set to one (two-sided chisquare test, $\mathrm{p}<0.0001)$. $\mathbf{d}$ Heatmap and hierarchical clustering based on the TOP100 differentially expressed piRNAs in control iPSCs/ESCs vs. neurons (sorted by adjusted p-value). Neurons (azure) are nicely separated from iPSCs (yellow) and ESCs (gold) 

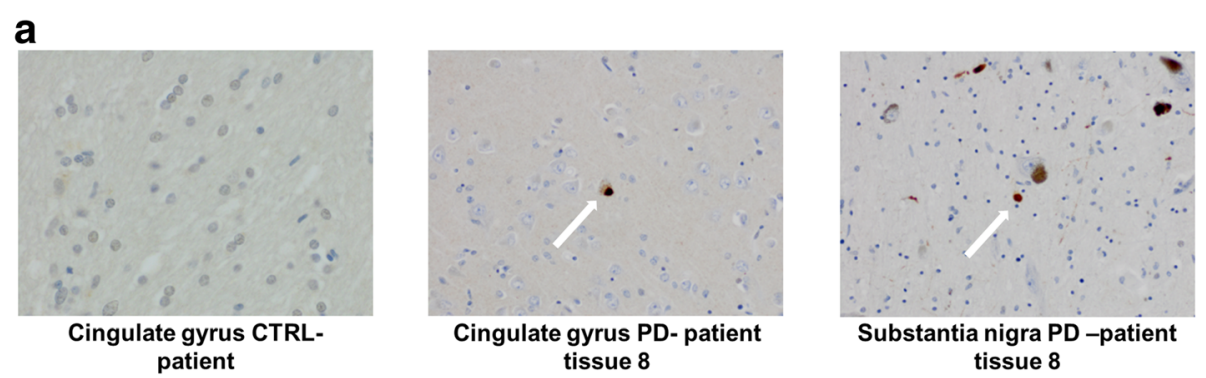

b
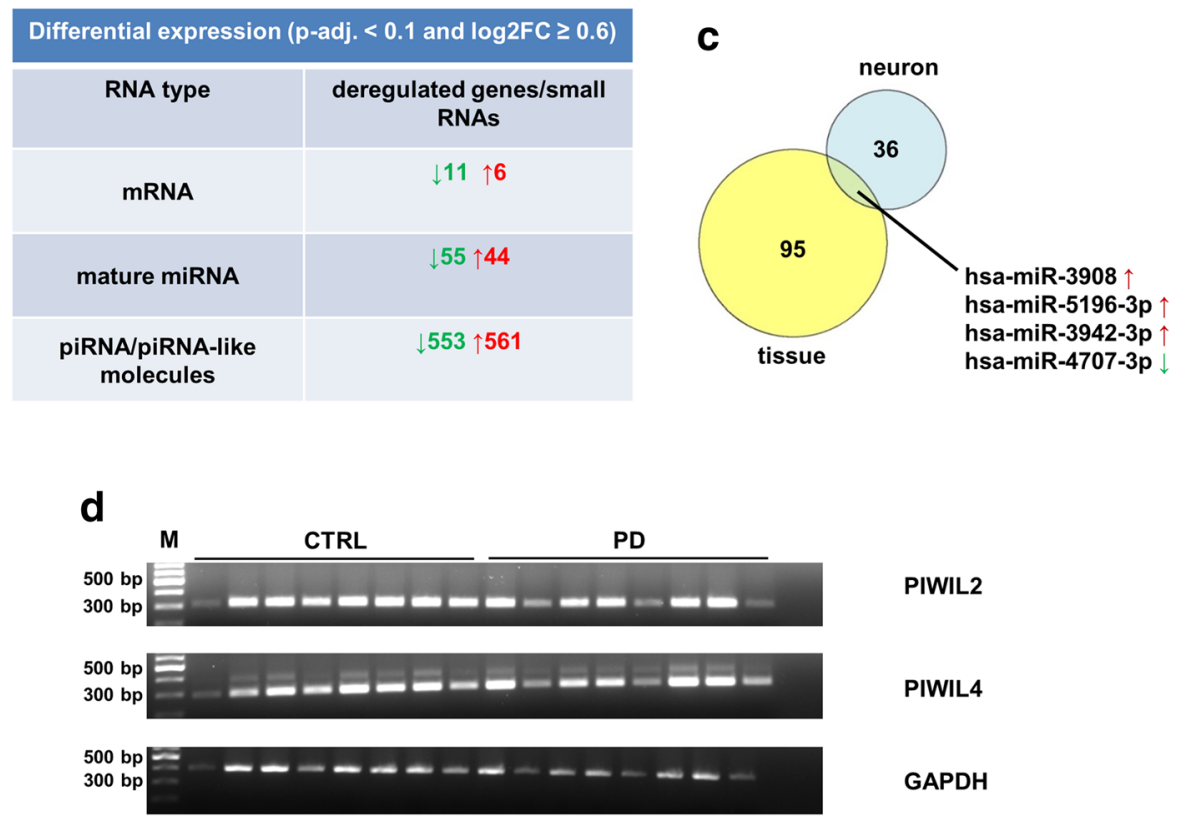

Fig. 5 Analysis of tissue samples underscores the relevance of piRNAs in PD. a Histology of a cingulate gyrus section of a healthy control, a substantia nigra section from a PD-patient (PD-patient 8 from the tissue cohort) and a cingulate gyrus section of the same patient all stained with an antibody directed against aggregated a-synuclein. Lewy bodies are present both in the cingulate gyrus as well as in the substantia nigra of the PD-patient. $\mathbf{b}$ Analysis of differential mRNA, mature miRNA and piRNA expression by DESeq2. There are significant differences between control- and PD-patients in every type of RNA. c Venn diagram of all common upregulated and downregulated mature miRNAs (log2FC $\geq 0.6, p-$ adj. $<0.1)$ in tissues and neurons. $\mathbf{d}$ Semiquantitative PCR of PIWIL2 and PIWIL4 in the tissues used for the analysis of small RNA expression patterns. Both genes are expressed in cingulate gyrus tissue. GAPDH was used as a loading control. A 100 bp DNA-ladder (M) was loaded together with the PCRs from control (CTRL) and PD-patient (PD) cingulate gyrus samples

more than 400,000 CpGs at a coverage $\geq 5 \times$ measured in every sample. We analysed 15 fibroblast lines $(n=6$ in the CTRL group and $n=9$ in the PD group), 28 pluripotent stem cell preparations $(n=16$ in the CTRL group and $n=12$ in the PD group), ten midbrain dopaminergic neurons $(n=5$ in the CTRL group and $n=5$ in the PD group). Sequences were highly enriched in $\mathrm{CpG}$ islands, CpG island shores and functional elements, as expected. There were differences in global methylation patterns between cell types, but not between PD- and control-patient derived cells (Additional file 13: Figure S6 A-C). Even after restricting the analysis to autosomes and stringent removal of low variability regions there were only very few differentially methylated CpGs (cut-off $\Delta$ meth $\geq 0.2$, p-adj. $<0.1$, data not shown) in fibroblasts
(36 CpGs), iPSCs (6 CpGs) or neurons (45 CpGs) and no difference in the mean methylation pattern of any well-covered (at least 5 CpGs per promoter with $5 \times$ coverage) gene promoter of known monogenic PD genes (Additional file 13: Figure S6D).

Thus, global methylation patterns that had been found to be reduced in late stage disease [33], were unaltered in vitro as judged by RRBS. This finding was confirmed in the tissues where no differences in methyl-cytosine staining could be observed between PD- and control-patients (Additional file 14: Figure S7). In comparison with a previous study [12] that reported global methylation differences between PD- and control-patient derived neurons we used another protocol for iPSC derivation as well as neuronal differentiation. We therefore conclude that in our 

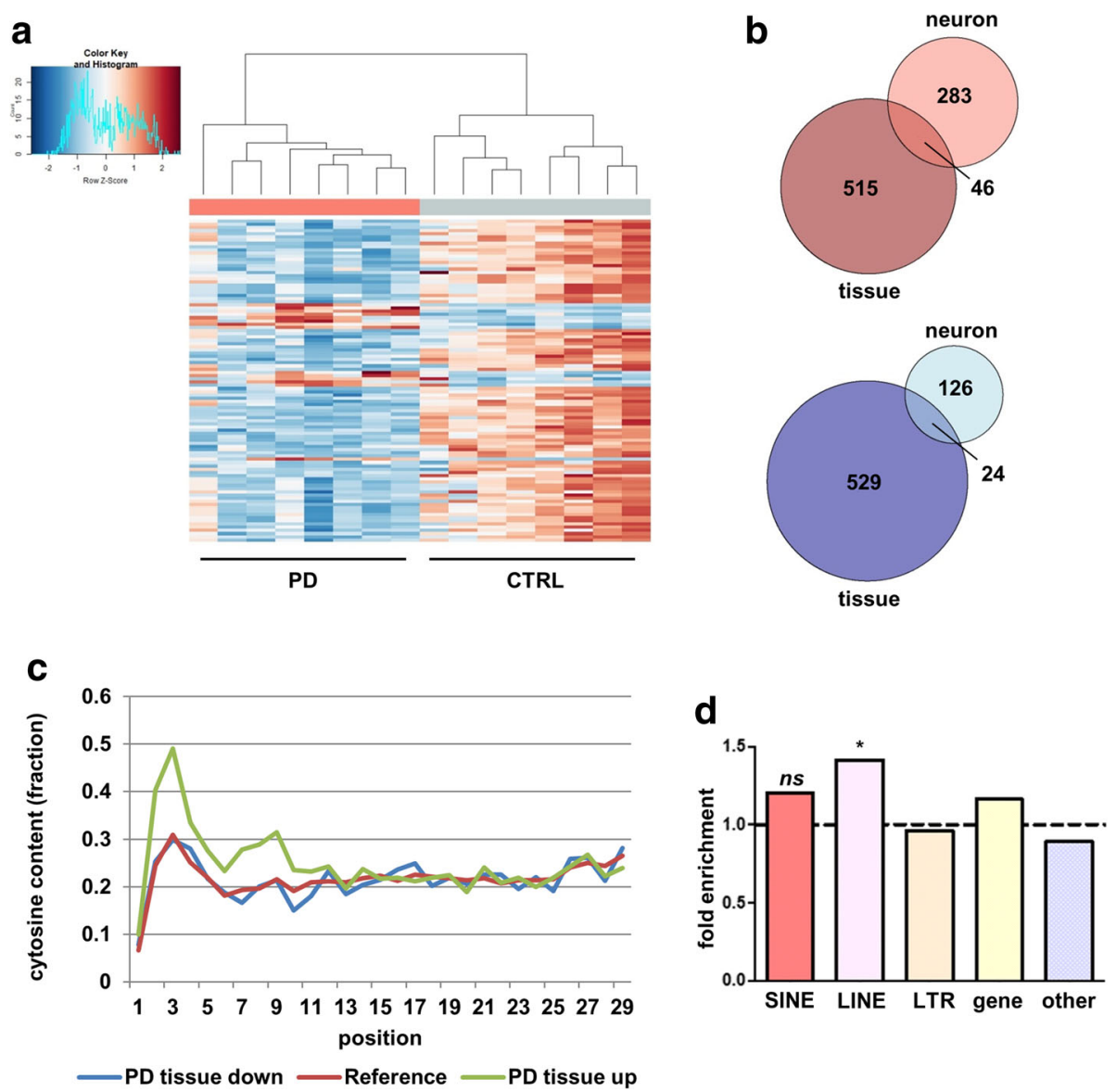

Fig. 6 Integration with tissue data identifies disease-relevant alterations in piRNAs in neurons. a Heatmap and hierarchical clustering based on the TOP100 differentially expressed piRNAs in tissues (sorted by adjusted p-value). PD-patient tissues (salmon) are clearly separated from controlpatient tissues (azure). b Venn diagrams of all upregulated and downregulated piRNAs in tissue and neurons. There are 70 shared piRNAs that may be suited as diagnostic markers. c Plot of cytosine content in all deregulated piRNAs over nucleotide positions 1 to 29 in tissue. In the first 10 nucleotides, cytosines are overrepresented in the upregulated piRNAs (green line) as compared to all piRNAs (dark red line). This phenomenon is not present in the downregulated piRNAs (blue line). $\mathbf{d}$ SINE- and LINE-derived piRNAs are enriched in the downregulated piRNA fraction in tissue. SINE- and LINE-derived piRNAs are enriched in the fraction of downregulated piRNAs as compared to their abundance in the genome, although this effect is only significant for LINE-derived piRNAs (two-sided chi-square test, $p<0.05$ )

experimental setup there is no methylation-based epigenetic memory or any disease-specific alteration in the CpG context in sporadic PD-patient derived cells.

Finally, we analysed mtDNA methylation patterns on the basis of our RRBS data as well as mtDNA mass and mtDNA deletions by real-time PCR. There were no significant differences between PD- and control-patient derived cells but again only between cell types themselves (Kruskall-Wallis test followed by Dunn's multiple comparison test, Additional file 15: Figure S8).

\section{Discussion}

Systematic screening for phenotypes in cells established from well-defined cohorts of sporadic PD-patients has not been performed, yet. Therefore, as part of the ForIPS consortium, we aimed to elucidate if sporadic PD-patient derived cells carry any alterations as compared to matched control patients. We can show that PD-patient derived cells show a specific small RNA signature in every cell type examined.

Several studies have suggested similarities between cells established from genetic and sporadic cases in certain assays $[12,18,54]$. To identify the molecular basis of such potential disease phenotypes we performed a comprehensive analysis of mRNA and small RNA expression patterns as well as methylation analysis at single base resolution in a unique cohort of fibroblasts, iPSCs and differentiated midbrain neurons from sporadic PD-patients. In classical phenotypic assays, the midbrain neurons differentiated from sporadic PD-patients did not show a cellular phenotype [59].

Nonetheless, on the mRNA level, the pathway regulating PGC1 $\alpha$ (peroxisome proliferator-activated receptor- $\gamma$ coactivator-1 $\alpha$ ) is inactivated in PD-patient derived 
midbrain neurons, which was previously reported to be involved in disease-specific phenotypes in an A53T model of PD [53] and is a hallmark of PD pathology [67]. PGC1 $\alpha$ is a master regulator of mitochondrial function and protects neurons from apoptotic cell death under stress conditions in in vitro models of PD [53, 67]. In addition, the CREB-(cAMP response element binding protein) pathway, which is a known neuroprotective pathway [23], was impaired in PD-patient derived neurons. CREB proteins, which are transcription factors mediating cAMP responses, (besides their function in cell survival) are involved in numerous processes in the nervous system, e.g. memory formation and neurogenesis [44]. Importantly, CREB-activity is modulated by PGC1 $\alpha$ [9] connecting the identified pathways on a functional level. On a single gene level we found a significant PD-associated effect on the transcriptome in differentiated neurons, while fibroblasts or iPSCs showed no differences. Among the genes deregulated in neuronal cells, there were several WNT-pathway members. These have been reported to be hypermethylated in PD [65] and upregulation of these genes in our midbrain neurons might serve as a protective mechanism as reported in a PD mouse model [31]. In addition, genes and pathways regulating neurodevelopment that function downstream of WNT signals and play a role in midbrain development, i.e. $L M X 1 B$ [29] and OTX2 [12], have been suggested to be involved in PD pathogenesis. We add the WNT-pathway members WNT3, ANT3A and WNT9B to this catalogue.

We furthermore show that neuronally differentiated cells show striking similarities with diseased tissue on the level of small RNAs. Here we detected the differential regulation of many PIWI interacting RNAs and/or piRNA-like molecules. Importantly, it has been reported by others that the orthologues of PIWI-proteins are expressed in the mammalian brain [37, 41]. Although piRNAs were first described in testes where they show the highest abundance [2], a large number of subsequent studies have identified their presence in the mammalian brain including studies on human tissue [10, 30, 41, 48, 52]. PiRNAs play an important role for retrotransposon silencing in the brain [41] and retrotransposon activation contributes to the genetic mosaicism in neurons in Drosophila [46]. Retrotransposon encoding loci are hypomethylated in mice deficient for a mouse orthologue of PIWI (MILI) [41]. On the functional level, chromatin modification and transcriptional repression are guided by piRNAs [19]. Moreover, piRNAs modulate synaptic plasticity in Aplysia neurons via CREB2 in response to serotonin [49] as well as dendritic spine size in mammalian cells [30]. Of note, others have recently described deregulated piRNA expression in Alzheimer's disease, emphasizing the relevance of piRNAs for neurodegenerative diseases $[48,52]$. We identfied a number of piRNAs that are shared between diseased PD-patient brain tissue and cultured neuronal cells. Importantly, the overrepresentation of LINE- and SINE-derived piRNAs among the downregulated piRNAs points towards a failure of PD-patient derived neurons to properly silence these elements. In addition, by analysing the size fraction of the piRNAs, we can show that both bona fide piRNAs as well as piRNA-like molecules contribute to the pool of deregulated sequences. This is important, as the catalogues of deregulated piRNAs in brain tissue from other diseases $[10,52,56]$ will most likely also contain a significant number of piRNA-like sequences. These are abundant outside of the testes [64], but their function is less well understood than that of canonical piRNAs.

It has been reported that sporadic PD-patient derived neurons show aberrant protein turnover, altered morphology and methylation patterns when compared to control-patient derived cells [12, 18, 54]. We extend these findings by completely tracing the cells on epigenomic and transcriptomic level from the primary fibroblasts through the iPSC stage to the neuronally differentiated stage. More importantly, we can show that the alterations are detectable with the widely used protocols of OKSM reprogramming followed by differentiation to midbrain neurons. Interestingly, neither on the methylation nor the small RNA level there were changes that would comprise a significant epigenetic memory. Only the PD-patient derived neurons had alterations that were comparable to the diseased tissue. However, we cannot completely rule out the possibility that epigenetic memory persists in epigenetic modifications that were not analysed in our study, e.g. on histones, as has been reported in other systems [17].

There may be some other limitations to our study that should be shortly mentioned: 1) We used a classical retroviral four factor reprogramming cocktail. Reprogramming with non-integrating vectors like Sendai-viruses or pure RNA may provide a platform for functional studies less prone to effects due to reprogramming factor integration into the genome. 2) Our study is focused on the analysis of mRNA/small RNA expression and DNA methylation patterns. Biochemical validation of the effects of deregulated piRNAs/piRNA-like molecules and pathways will be an active area of future research when the appropriate tools are available. 3) Further examination of cortically differentiated neurons and/or laser capture microdissection of purified dopaminergic neurons from the substantia nigra could support and refine the conclusions on disease etiology of different types of neurons both in the in vitro and in vivo setting.

Nonetheless, our study implies that disease modelling with cells derived from sporadic PD cases is possible. We conclude that although four factor reprogramming 
removes ageing associated marks [39] and iPSCs from healthy individuals are equivalent to ESCs [5, 8], Parkinson's disease derived neuronal cells show disease-specific alterations on transcriptomic and epigenetic level. More importantly, we show that both in neurons and in post-mortem brain tissue from PD-patients, piRNAs are deregulated in a similar fashion, which is a striking new finding both in the field of PD as well as cell biology research. We support this findings with a total number of more than 200 next-generation sequencing runs (DNA methylation, microRNAs, mRNAs) on one of the largest collectives of high-quality PD-derived cell preparations that is available in the field.

\section{Additional files}

Additional file 1: Table S1. Cohort statistics with details about age, gender and all other covariates used for differential expression models. (XLSX $19 \mathrm{~kb})$

Additional file 2: Figure S1. Analysis of pluripotency marker expression. (TIF $403 \mathrm{~kb}$ )

Additional file 3: Figure S2. mRNA based analysis of neuronal differentiation. (TIF $1295 \mathrm{~kb}$ )

Additional file 4: Table S2. Differential expression analysis for mRNAs in fibroblasts, IPSCS/ESCs and neurons for the comparison PD vs. CTRL. (XLSX $18407 \mathrm{~kb})$

Additional file 5: Table S3. Gene set enrichment analysis in neurons for the comparison PD vs. CTRL (based on mRNA-RPKM data) for Biocarta and KEGG pathways. (XLSX $1121 \mathrm{~kb}$ )

Additional file 6: Figure S3. Differential expression of mature miRNAs in vitro. (TIF $447 \mathrm{~kb}$ )

Additional file 7: Table S4. Differential expression analysis for mature miRNAs in fibroblasts, iPSCs/ESCs and neurons for the comparison PD vs. CTRL. (XLSX $718 \mathrm{~kb})$

Additional file 8: Table S5. Differential expression analysis for piRNAs/ piRNA-like molecules in fibroblasts, iPSCs/ESCs and neurons for the comparison PD vs. CTRL. (XLSX $10389 \mathrm{~kb}$ )

Additional file 9: Figure S4. Small RNA content analysis and library size distribution. (TIF $491 \mathrm{~kb}$ )

Additional file 10: Table S6. Differential expression analysis for piRNAs/ piRNA-like molecues and mature miRNAs for the comparison control fibroblasts vs. control iPSCs/ESCs and control iPSCs/ESCs vs. control neurons. (XLSX $7706 \mathrm{~kb}$ )

Additional file 11: Figure S5. Analysis of cell type abundance and marker genes in tissues. (TIF $524 \mathrm{~kb}$ )

Additional file 12: Table S7. Differential expression analysis for mRNAs, mature miRNAs and piRNAs/piRNA-like molecules in tissues for the comparison PD vs. CTRL. (XLSX $9950 \mathrm{~kb})$

Additional file 13: Figure S6. Global statistics on RRBS and analysis of differential methylation. (TIF $351 \mathrm{~kb}$ )

Additional file 14: Figure S7. Immunohistochemical staining for methyl-cytosine in all eight control- and PD-patients. (TIF $3846 \mathrm{~kb}$ )

Additional file 15: Figure S8. Analysis of mtDNA parameters. (TIF $416 \mathrm{~kb}$ )

\section{Acknowledgements}

We thank André Reis and Mandy Krumbiegel (Department of Human Genetics, FAU, Erlangen University Hospital, Erlangen, Germany) for critical discussion on the topic. We thank Shunmin He and Peng Zhang (Key Laboratory of the Zoological Systematics and Evolution, Institute of Zoology,
Chinese Academy of Sciences, Beijing 100101, China) for their help on piRNAs.

\section{Author contributions}

Conception and design: RMJ, WJ, WB. Development of methodology: RMJ, WB, SM, SA, GJ. Acquisition of data: SM, SA, GJ, PS, FM. Analysis and interpretation of data: SM, RMJ. Writing, review and/or revision of the manuscript: SM, RMJ, WB, WJ, SA, GJ. Administrative, technical, or material support: SA, GJ, PS, FM. Study supervision: RMJ, WB, WJ. All authors read and approved the final manuscript.

Ethics approval, consent to participate and consent for publication The Institutional Review Board approval (Nr. 4120: Generierung von humanen neuronalen Modellen bei neurodegenerativen Erkrankungen) and informed consent forms are on file at the movement disorder clinic at the Department of Molecular Neurology, Universitätsklinikum Erlangen (Erlangen, Germany). The experiments involving embryonic stem celle were approved by the Central Ethics Committee for Stem Cell Research in Germany according to StZG (AZ: 3.04.02/0121).

\section{Funding}

This study was funded by the Bavarian Research Network on induced pluripotent stem cells (ForlPS). Additional support came from the GRK2162 (to BW, JW) and IZKF E25, BMBF 01GM1520A and BMBF 01EK1609B (to BW)

Availability of data and materials

All normalized NGS data were deposited in GEO (URL: https:// www.ncbi.nlm.nih.gov/geo) under the super series accession GSE110720.

\section{Competing interests}

The authors declare they have no competing interests.

\section{Publisher's Note}

Springer Nature remains neutral with regard to jurisdictional claims in published maps and institutional affiliations.

\section{Author details}

'Department of Neuropathology, Regensburg University Hospital, Franz-Josef-Strauss-Allee 11, 93053 Regensburg, Germany. ${ }^{2}$ Department of Stem Cell Biology, Friedrich-Alexander University (FAU) Erlangen-Nürnberg, Erlangen, Germany. ${ }^{3}$ Department of Molecular Neurology, FAU Erlangen-Nürnberg, Erlangen, Germany. ${ }^{4}$ Present address: Division of Molecular Genetics, German Cancer Research Center (DKFZ), Im Neuenheimer Feld 580, 69120 Heidelberg, Germany.

Received: 27 June 2018 Accepted: 27 June 2018 Published online: 10 July 2018

References

1. Abyzov A, Mariani J, Palejev D, Zhang Y, Haney MS, Tomasini L, Ferrandino AF, Rosenberg Belmaker LA, Szekely A, al WM (2012) Somatic copy number mosaicism in human skin revealed by induced pluripotent stem cells. Nature 492:438-442. https://doi.org/10.1038/nature11629

2. Aravin $A$, Gaidatzis $D$, Pfeffer $S$, Lagos-Quintana M, Landgraf P, lovino N, Morris P, Brownstein MJ, Kuramochi-Miyagawa S, al NT (2006) A novel class of small RNAs bind to MILI protein in mouse testes. Nature 442:203-207. https://doi.org/10.1038/nature04916

3. Asikainen S, Rudgalvyte M, Heikkinen L, Louhiranta K, Lakso M, Wong G, Nass R (2010) Global microRNA expression profiling of Caenorhabditis elegans Parkinson's disease models. Journal of molecular neuroscience : MN 41:210-218. https://doi.org/10.1007/s12031-009-9325-1

4. Assenov Y, Muller F, Lutsik P, Walter J, Lengauer T, Bock C (2014) Comprehensive analysis of DNA methylation data with RnBeads. Nat Methods 11:1138-1140. https://doi.org/10.1038/nmeth.3115

5. Bock C, Kiskinis E, Verstappen G, Gu H, Boulting G, Smith ZD, Ziller M, Croft GF, Amoroso MW, al ODH (2011) Reference Maps of human ES and iPS cell variation enable high-throughput characterization of pluripotent cell lines. Cell 144:439-452. https://doi.org/10.1016/i.Cell2010.12.032

6. Cahoy JD, Emery B, Kaushal A, Foo LC, Zamanian JL, Christopherson KS, Xing Y, Lubischer JL, Krieg PA, al KSA (2008) A transcriptome database for astrocytes, neurons, and oligodendrocytes: a new resource for 
understanding brain development and function. J Neurosci 28:264-278. https://doi.org/10.1523/JNEUROSCI.4178-07.2008

7. Chamberlain SJ, Chen PF, Ng KY, Bourgois-Rocha F, Lemtiri-Chlieh F, Levine ES, Lalande M (2010) Induced pluripotent stem cell models of the genomic imprinting disorders Angelman and Prader-Willi syndromes. Proc Natl Acad Sci U S A 107:17668-17673. https://doi.org/10.1073/pnas.1004487107

8. Choi J, Lee S, Mallard W, Clement K, Tagliazucchi GM, Lim H, Choi IY, Ferrari F, Tsankov AM, al PR (2015) A comparison of genetically matched cell lines reveals the equivalence of human IPSCs and ESCs. Nat Biotechnol 33:11731181. https://doi.org/10.1038/nbt.3388

9. Dankel SN, Hoang T, Flageng MH, Sagen JV, Mellgren G (2010) CAMPmediated regulation of HNF-4alpha depends on the level of coactivator PGC-1alpha. Biochim Biophys Acta 1803:1013-1019. https://doi.org/10.1016/ j.bbamcr.2010.05.008

10. Dharap A, Nakka VP, Vemuganti R (2011) Altered expression of PIWI RNA in the rat brain after transient focal ischemia. Stroke 42:1105-1109. https://doi. org/10.1161/STROKEAHA.110.598391

11. Dolle C, Flones I, Nido GS, Miletic H, Osuagwu N, Kristoffersen S, Lilleng PK, Larsen JP, Tysnes OB, al HK (2016) Defective mitochondrial DNA homeostasis in the substantia nigra in Parkinson disease. Nat Commun 7: 13548. https://doi.org/10.1038/ncomms13548

12. Fernandezsantiago R, Carballo-Carbajal I, Castellano G, Torrent R, Richaud Y, Sanchez-Danes A, Vilarrasa-Blasi R, Sanchez-Pla A, Mosquera JL, Soriano J et al (2015) Aberrant epigenome in iPSC-derived dopaminergic neurons from Parkinson's disease patients. EMBO Mol Med 7:1529-1546. https://doi.org/10 15252/emmm.201505439

13. Girard A, Sachidanandam R, Hannon GJ, Carmell MA (2006) A germlinespecific class of small RNAs binds mammalian Piwi proteins. Nature 442: 199-202. https://doi.org/10.1038/nature04917

14. Goedert M, Jakes R, Crowther RA, Six J, Lubke U, Vandermeeren M, Cras P, Trojanowski JQ, Lee VM (1993) The abnormal phosphorylation of tau protein at Ser-202 in Alzheimer disease recapitulates phosphorylation during development. Proc Natl Acad Sci U S A 90:5066-5070

15. Havlicek S, Kohl Z, Mishra HK, Prots I, Eberhardt E, Denguir N, Wend H, Plotz S, Boyer L, al MMC (2014) Gene dosage-dependent rescue of HSP neurite defects in SPG4 patients' neurons. Human molecular genetics 23:2527-2541. https://doi.org/10.1093/hmg/ddt644

16. Hiler D, Chen X, Hazen J, Kupriyanov S, Carroll PA, Qu C, Xu B, Johnson D, Griffiths L, al FS (2015) Quantification of Retinogenesis in 3D Cultures Reveals Epigenetic Memory and Higher Efficiency in iPSCs Derived from Rod Photoreceptors. Cell Stem Cell 17:101-115. https://doi.org/10.1016/j. stem.2015.05.015

17. Hormanseder E, Simeone A, Allen GE, Bradshaw CR, Figlmuller M, Gurdon J, Jullien J (2017) H3K4 methylation-dependent memory of somatic cell identity inhibits reprogramming and development of nuclear transfer embryos. Cell Stem Cell 21(135-143):e136. https://doi.org/10.1016/.stem.2017.03.003

18. Hsieh CH, Shaltouki A, Gonzalez AE, Bettencourt da Cruz A, Burbulla LF, St Lawrence E, Schule B, Krainc D, Palmer TD, Wang X (2016) Functional impairment in Miro degradation and Mitophagy is a shared feature in familial and sporadic Parkinson's disease. Cell Stem Cell 19:709-724. https:// doi.org/10.1016/j.stem.2016.08.002

19. Huang XA, Yin H, Sweeney S, Raha D, Snyder M, Lin H (2013) A major epigenetic programming mechanism guided by piRNAs. Dev Cell 24:502516. https://doi.org/10.1016/j.devcel.2013.01.023

20. Huber W, Carey VJ, Gentleman R, Anders S, Carlson M, Carvalho BS, Bravo HC, Davis S, Gatto L, Girke T et al (2015) Orchestrating high-throughput genomic analysis with Bioconductor. Nat Methods 12:115-121. https://doi. org/10.1038/nmeth.3252

21. Imaizumi Y, Okada Y, Akamatsu W, Koike M, Kuzumaki N, Hayakawa H, Nihira T, Kobayashi T, Ohyama M, al SS (2012) Mitochondrial dysfunction associated with increased oxidative stress and alpha-synuclein accumulation in PARK2 iPSC-derived neurons and postmortem brain tissue. Mol Brain 5:35. https://doi.org/10.1186/1756-6606-5-35

22. Itoh Y, Voskuhl RR (2017) Cell specificity dictates similarities in gene expression in multiple sclerosis, Parkinson's disease, and Alzheimer's disease. PLoS One 12:e0181349. https://doi.org/10.1371/journal.pone.0181349

23. Jensen P, Myhre CL, Lassen PS, Metaxas A, Khan AM, Lambertsen KL, Babcock AA, Finsen B, Larsen MR, Kempf SJ (2017) TNFalpha affects CREBmediated neuroprotective signaling pathways of synaptic plasticity in neurons as revealed by proteomics and phospho-Proteomics. Oncotarget. https://doi.org/10.18632/oncotarget.19428
24. Kaut O, Schmitt I, Tost J, Busato F, Liu Y, Hofmann P, Witt SH, Rietschel M, Frohlich H, Wullner U (2017) Epigenome-wide DNA methylation analysis in siblings and monozygotic twins discordant for sporadic Parkinson's disease revealed different epigenetic patterns in peripheral blood mononuclear cells. Neurogenetics 18:7-22. https://doi.org/10.1007/s10048-016-0497-x

25. Kaut O, Schmitt I, Wullner U (2012) Genome-scale methylation analysis of Parkinson's disease patients' brains reveals DNA hypomethylation and increased mRNA expression of cytochrome P450 2E1. Neurogenetics 13:8791. https://doi.org/10.1007/s10048-011-0308-3

26. Kim J, Inoue K, Ishii J, Vanti WB, Voronov SV, Murchison E, Hannon G, Abeliovich A (2007) A MicroRNA feedback circuit in midbrain dopamine neurons. Science 317:1220-1224. https://doi.org/10.1126/science.1140481

27. Koyanagi-Aoi M, Ohnuki M, Takahashi K, Okita K, Noma H, Sawamura Y, Teramoto I, Narita M, Sato Y, al IT (2013) Differentiation-defective phenotypes revealed by large-scale analyses of human pluripotent Stem Cells. Proc Natl Acad Sci U S A 110:20569-20574. https://doi.org/10.1073/ pnas. 1319061110

28. Krueger F, Andrews SR (2011) Bismark: a flexible aligner and methylation caller for bisulfite-Seq applications. Bioinformatics 27:1571-1572. https://doi. org/10.1093/bioinformatics/btr167

29. Laguna A, Schintu N, Nobre A, Alvarsson A, Volakakis N, Jacobsen JK, Gomez-Galan M, Sopova E, Joodmardi E, al YT (2015) Dopaminergic control of autophagic-lysosomal function implicates $L m \times 1 b$ in Parkinson's disease. Nat Neurosci 18:826-835. https://doi.org/10.1038/nn.4004

30. Lee EJ, Banerjee S, Zhou H, Jammalamadaka A, Arcila M, Manjunath BS, Kosik KS (2011) Identification of piRNAs in the central nervous system. RNA 17:1090-1099. https://doi.org/10.1261/rna.2565011

31. L'Episcopo F, Tirolo C, Testa N, Caniglia S, Morale MC, Serapide MF, Pluchino S, Marchetti B (2014) Wnt/beta-catenin signaling is required to rescue midbrain dopaminergic progenitors and promote neurorepair in ageing mouse model of Parkinson's disease. Stem Cells 32:2147-2163. https://doi. org/10.1002/stem.1708

32. Lestrade L, Weber MJ (2006) snoRNA-LBME-db, a comprehensive database of human H/ACA and C/D box snoRNAs. Nucleic Acids Res 34:D158-D162. https://doi.org/10.1093/nar/gkj002

33. Li W, Englund E, Widner H, Mattsson B, van Westen D, Latt J, Rehncrona S, Brundin P, Bjorklund A, al LO (2016) Extensive graft-derived dopaminergic innervation is maintained 24 years after transplantation in the degenerating parkinsonian Brain. Proc Natl Acad Sci U S A. https://doi.org/10.1073/pnas. 1605245113

34. Lin L, Goke J, Cukuroglu E, Dranias MR, VanDongen AM, Stanton LW (2016) Molecular features underlying neurodegeneration identified through in vitro modeling of genetically diverse Parkinson's disease patients. Cell Rep 15: 2411-2426. https://doi.org/10.1016/j.celrep.2016.05.022

35. Livak KJ, Schmittgen TD (2001) Analysis of relative gene expression data using real-time quantitative PCR and the 2(-Delta Delta C(T)) method. Methods 25:402-408. https://doi.org/10.1006/meth.2001.1262

36. Love MI, Huber W, Anders S (2014) Moderated estimation of fold change and dispersion for RNA-seq data with DESeq2. Genome Biol 15:550. https:// doi.org/10.1186/s13059-014-0550-8

37. Mani SR, Juliano CE (2013) Untangling the web: the diverse functions of the PIWI/piRNA pathway. Mol Reprod Dev 80:632-664. https://doi.org/10.1002/ mrd.22195

38. Martin I, Dawson VL, Dawson TM (2011) Recent advances in the genetics of Parkinson's disease. Annu Rev Genomics Hum Genet 12:301-325. https:// doi.org/10.1146/annurev-genom-082410-101440

39. Mertens J, Paquola AC, Ku M, Hatch E, Bohnke L, Ladjevardi S, McGrath S, Campbell B, Lee H, al HJR (2015) Directly Reprogrammed Human Neurons Retain Aging-Associated Transcriptomic Signatures and Reveal Age-Related Nucleocytoplasmic Defects. Cell Stem Cell 17:705-718. https://doi.org/10. 1016/.jstem.2015.09.001

40. Muller FJ, Schuldt BM, Williams R, Mason D, Altun G, Papapetrou EP, Danner S, Goldmann JE, Herbst A, al SNO (2011) A bioinformatic assay for pluripotency in human cell. Nat Methods 8:315-317. https://doi.org/10. 1038/nmeth.1580

41. Nandi S, Chandramohan D, Fioriti L, Melnick AM, Hebert JM, Mason CE, Rajasethupathy P, Kandel ER (2016) Roles for small noncoding RNAs in silencing of retrotransposons in the mammalian brain. Proc Natl Acad Sci U S A. https://doi.org/10.1073/pnas.1609287113

42. Nguyen HN, Byers B, Cord B, Shcheglovitov A, Byrne J, Gujar P, Kee K, Schule B, Dolmetsch RE, al LW (2011) LRRK2 mutant iPSC-derived DA 
neurons demonstrate increased susceptibility to oxidative stress. Cell Stem Cell 8:267-280. https://doi.org/10.1016/j.stem.2011.01.013

43. Ohi Y, Qin H, Hong C, Blouin L, Polo JM, Guo T, Qi Z, Downey SL, Manos PD, al RDJ (2011) Incomplete DNA methylation underlies a transcriptional memory of somatic cells in human iPS cells. Nat Cell Biol 13:541-549. https://doi.org/10.1038/ncb2239

44. Ortega-Martinez S (2015) A new perspective on the role of the CREB family of transcription factors in memory consolidation via adult hippocampal neurogenesis. Front Mol Neurosci 8:46. https://doi.org/10.3389/fnmol.2015. 00046

45. Pang KC, Stephen S, Dinger ME, Engstrom PG, Lenhard B, Mattick JS (2007) RNAdb 2.0-an expanded database of mammalian non-coding RNAs. Nucleic Acids Res 35:D178-D182. https://doi.org/10.1093/nar/gkl926

46. Perrat PN, DasGupta S, Wang J, Theurkauf W, Weng Z, Rosbash M, Waddell S (2013) Transposition-driven genomic heterogeneity in the Drosophila brain. Science 340:91-95. https://doi.org/10.1126/science.1231965

47. Qiu L, Zhang W, Tan EK, Zeng L (2014) Deciphering the function and regulation of microRNAs in Alzheimer's disease and Parkinson's disease. ACS Chem Neurosci 5:884-894. https://doi.org/10.1021/cn500149w

48. Qiu W, Guo X, Lin X, Yang Q, Zhang W, Zhang Y, Zuo L, Zhu Y, Li CR, al Ma C (2017) Transcriptome-wide piRNA profiling in human brains of Alzheimer's disease. Neurobiol Aging 57:170-177. https://doi.org/10.1016/j. neurobiolaging.2017.05.020

49. Rajasethupathy P, Antonov I, Sheridan R, Frey S, Sander C, Tuschl T, Kandel ER (2012) A role for neuronal piRNAs in the epigenetic control of memoryrelated synaptic plasticity. Cell 149:693-707. https://doi.org/10.1016/j.cell. 2012.02.057

50. Reinhardt P, Glatza M, Hemmer K, Tsytsyura Y, Thiel CS, Hoing S, Moritz S, Parga JA, Wagner L, al BJM (2013) Derivation and expansion using only small molecules of human neural progenitors for neurodegenerative disease modeling. PLoS One 8:e59252. https://doi.org/10.1371/journal.pone. 0059252

51. Rooney JP, Ryde IT, Sanders LH, Howlett EH, Colton MD, Germ KE, Mayer GD, Greenamyre JT, Meyer JN (2015) PCR based determination of mitochondrial DNA copy number in multiple species. Methods Mol Biol 1241:23-38. https://doi.org/10.1007/978-1-4939-1875-1_3

52. Roy J, Sarkar A, Parida S, Ghosh Z, Mallick B (2017) Small RNA sequencing revealed dysregulated piRNAs in Alzheimer's disease and their probable role in pathogenesis. Mol BioSyst 13:565-576. https://doi.org/10.1039/ c6mb00699j

53. Ryan SD, Dolatabadi N, Chan SF, Zhang X, Akhtar MW, Parker J, Soldner F, Sunico CR, Nagar S, al TM (2013) Isogenic human iPSC Parkinson's model shows nitrosative stress-induced dysfunction in MEF2-PGC1alpha transcription. Cell 155:1351-1364. https://doi.org/10.1016/j.cell.2013.11.009

54. Sanchez-Danes A, Richaud-Patin Y, Carballo-Carbajal I, Jimenez-Delgado S, Caig C, Mora S, Di Guglielmo C, Ezquerra M, Patel B, al GA (2012) Diseasespecific phenotypes in dopamine neurons from human iPS-based models of genetic and sporadic Parkinson's disease. EMBO Mol Med 4:380-395. https://doi.org/10.1002/emmm.201200215

55. Sandor C, Honti F, Haerty W, Szewczyk-Krolikowski K, Tomlinson P, Evetts S, Millin S, Keane T, McCarthy SA, al DR (2017) Whole-exome sequencing of 228 patients with sporadic Parkinson's disease. Sci Rep 7:41188. https://doi. org/10.1038/srep41188

56. Saxena A, Tang D, Carninci P (2012) piRNAs warrant investigation in Rett syndrome: an omics perspective. Dis Markers 33:261-275. https://doi.org/10. 3233/DMA-2012-0932

57. Schulze M, Hoja S, Winner B, Winkler J, Edenhofer F, Riemenschneider MJ (2016) Model testing of PluriTest with next-generation sequencing data. Stem Cells Dev 25:569-571. https://doi.org/10.1089/scd.2015.0266

58. Smith GA, Jansson J, Rocha EM, Osborn T, Hallett PJ, Isacson O (2015) Fibroblast biomarkers of sporadic Parkinson's disease and LRRK2 kinase inhibition. Mol Neurobiol. https://doi.org/10.1007/s12035-015-9435-4

59. Sommer A, Maxreiter F, Krach F, Grosch J, Fadler T, Maroni M, Gräf D, Eberhardt E, Riemenschneider MJ, Yeo Get al (2018) Th17 lymphocyteinduced neuronal cell death in Parkinson's disease. Cell Stem Cell 23:123-131. https://doi.org/10.1016/.jtem.2018.06.015

60. Sugimoto K, Kage H, Aki N, Sano A, Kitagawa H, Nagase T, Yatomi Y, Ohishi $\mathrm{N}$, Takai D (2007) The induction of H3K9 methylation by PIWIL4 at the p16Ink4a locus. Biochem Biophys Res Commun 359:497-502. https://doi. org/10.1016/j.bbrc.2007.05.136
61. Untergasser A, Nijveen H, Rao X, Bisseling T, Geurts R, Leunissen JA (2007) Primer3Plus, an enhanced web interface to Primer3. Nucleic Acids Res 35 W71-W74. https://doi.org/10.1093/nar/gkm306

62. Vitaloni M, Pulecio J, Bilic J, Kuebler B, Laricchia-Robbio L, Izpisua Belmonte JC (2014) MicroRNAs contribute to induced pluripotent stem cell somatic donor memory. J Biol Chem 289:2084-2098. https://doi.org/10.1074/jbc. M113.538702

63. Wang X, Spandidos A, Wang H, Seed B (2012) PrimerBank: a PCR primer database for quantitative gene expression analysis, 2012 update. Nucleic Acids Res 40:D1144-D1 149. https://doi.org/10.1093/nar/gkr1013

64. Yan Z, Hu HY, Jiang X, Maierhofer V, Neb E, He L, Hu Y, Hu H, Li N, al CW (2011) Widespread expression of piRNA-like molecules in somatic tissues. Nucleic Acids Res 39:6596-6607. https://doi.org/10.1093/nar/gkr298

65. Zhang L, Deng J, Pan Q, Zhan Y, Fan JB, Zhang K, Zhang Z (2016) Targeted methylation sequencing reveals dysregulated Wnt signaling in Parkinson disease. J Genet Genomics 43:587-592. https://doi.org/10.1016/j.jgg.2016.05. 002

66. Zhang P, Si X, Skogerbo G, Wang J, Cui D, Li Y, Sun X, Liu L, Sun B, Chen R et al. (2014) piRBase: a web resource assisting piRNA functional study. Database (Oxford) 2014: bau110 doi https://doi.org/10.1093/database/ bau110

67. Zheng B, Liao Z, Locascio JJ, Lesniak KA, Roderick SS, Watt ML, Eklund AC, Zhang-James Y, Kim PD, al HMA (2010) PGC-1alpha, a potential therapeutic target for early intervention in Parkinson's disease. Sci Transl Med 2:52ra73. https://doi.org/10.1126/scitranslmed.3001059

68. Zuo L, Wang Z, Tan Y, Chen X, Luo X (2016) piRNAs and their functions in the brain. Int J Hum Genet 16:53-60

\section{Ready to submit your research? Choose BMC and benefit from:}

- fast, convenient online submission

- thorough peer review by experienced researchers in your field

- rapid publication on acceptance

- support for research data, including large and complex data types

- gold Open Access which fosters wider collaboration and increased citations

- maximum visibility for your research: over $100 \mathrm{M}$ website views per year

At BMC, research is always in progress.

Learn more biomedcentral.com/submissions 